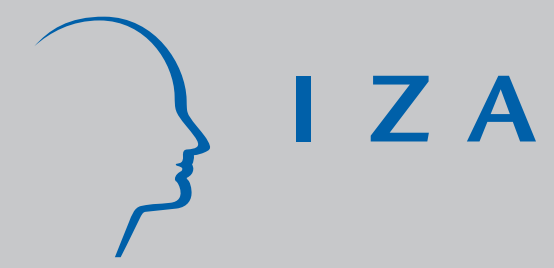

IZA DP No. 94

An Evaluation of Public Employment Programmes in the East German State of Sachsen-Anhalt

Michael Lechner

Martin Eichler

December 1999 


\title{
An Evaluation of \\ Public Employment Programmes in the East German State of Sachsen-Anhalt
}

\author{
Martin Eichler \\ University of St. Gallen \\ Michael Lechner \\ University of St. Gallen \\ Discussion Paper No. 94 \\ December 1999 \\ IZA \\ P.O. Box 7240 \\ D-53072 Bonn \\ Germany \\ Tel.: +49-228-3894-0 \\ Fax: +49-228-3894-210 \\ Email: iza@iza.org
}

This Discussion Paper is issued within the framework of IZA's research area Project Evaluation. Any opinions expressed here are those of the author(s) and not those of the institute. Research disseminated by IZA may include views on policy, but the institute itself takes no institutional policy positions.

The Institute for the Study of Labor (IZA) in Bonn is a local and virtual international research center and a place of communication between science, politics and business. IZA is an independent, nonprofit limited liability company (Gesellschaft mit beschränkter Haftung) supported by the Deutsche Post AG. The center is associated with the University of Bonn and offers a stimulating research environment through its research networks, research support, and visitors and doctoral programs. IZA engages in (i) original and internationally competitive research in all fields of labor economics, (ii) development of policy concepts, and (iii) dissemination of research results and concepts to the interested public. The current research program deals with (1) mobility and flexibility of labor markets, (2) internationalization of labor markets and European integration, (3) the welfare state and labor markets, (4) labor markets in transition, (5) the future of work, (6) project evaluation and (7) general labor economics.

IZA Discussion Papers often represent preliminary work and are circulated to encourage discussion. Citation of such a paper should account for its provisional character. 
IZA Discussion Paper No. 94

December 1999

\section{ABSTRACT}

\section{An Evaluation of \\ Public Employment Programmes in the East German State of Sachsen-Anhalt}

In East Germany, active labour market policies (ALMPs) are used on a large scale to contain fast rising unemployment after unification. This paper evaluates the effects for participants in public employment programmes (PEPs), that are an important part of ALMPs. It focuses on individual unemployment probabilities. By concentrating on the state of Sachsen-Anhalt, the econometric analysis can use a new and large panel, the Arbeitsmarktmonitor SachsenAnhalt. We aim at nonparametric identification of the effects of PEPs by combining the use of comparison groups with differencing over time to correct for selection effects. Our results indicate that PEP participation reduces the unemployment risk of the participants.

JEL Classification: C14, C23, H43, J64, J68

Keywords: East German labour markets, treatment effects, panel data, matching, differences-in-differences

Michael Lechner

University of St. Gallen

Swiss Institute for International Economics and Applied Economic Research (SIAW)

Dufourstr. 48

$\mathrm{CH}-9000$ St. Gallen

Switzerland

Email: Michael.Lechner@unisg.ch

\footnotetext{
"Financial support from the Deutsche Forschungsgemeinschaft (DFG) grant LE 928/2-2 and the Schweizer Nationalfond (SNF) grant 1214-53735 is gratefully acknowledged. The paper has been presented at seminars at the University of Bem, the Institut für Wirtschaftsforschung Halle, the Department of Economics at the University of Strasbourg, and the Department of Economic Statistics at the Stockholm School of Economics, at the 8th Conference on Panel Data in Göteborg, the Germany's Labor Market Problems: An Empirical Assessment Research Conference in Berlin, the European Meeting of the Econometric Society 1998 in Berlin, the Jahrestagung des Ausschusses für Ökonometrie des Vereins für Socialpolitik 1999 in Rauischholzhausen, the Tagung der Studiengruppe Ökonometrie und Statistik der Schweizerischen Gesellschaft für Volkswirtschaftslehre und Statistik 1999 in Zürich, the 11 th European Association of Labour Economists Conference 1999 in Regensburg, and the Jahrestagung des Vereins für Socialpolitik 1999 in Mainz. We thank participants for helpful comments and suggestions. Furthermore, we thank Knut Emmerich for the information on differences of the Public Employment Programmes between the new federal states. The help of Lothar Essig, Joachim Fox, Marcus Bergsträßer, Julien Penin, and Heidi Steiger with the data is appreciated.
} 


\section{Introduction}

After unification, the East German economy changed quite dramatically. On the labour market under- and unemployment rose. Programmes of active labour market policy (ALMP) were set up. Quickly a huge number of people participated in these programmes, but at the same time ALMP absorbed considerable amounts of money. Public employment programmes (Arbeitsbeschaffungsmassnahmen, PEPs) are an important part of ALMP. PEPs create additional jobs in the public or private sector through a wage subsidy paid by the labour office. More than 2 million people participated in some kind of PEPs since 1990. The main goal of PEPs is the reduction of unemployment, directly as well as through improving employment chances of PEP participants on the regular labour market by providing work experience and informal training. In this microeconometric evaluation study we try to answer the question about the effects of PEPs for participants after they left PEP.

There are only few econometric evaluation studies of PEPs in East Germany. ${ }^{1}$ Steiner and Kraus (1995) evaluate PEPs in East Germany with data from 1990 to 1992 using duration models. They find a higher probability for men after twelve months PEP participation to move to employment compared to non-participants. In a more recent work (Kraus, Puhani, and Steiner, 1998), using more data and improved methods, they find a significant negative effect. Both papers are based on the East German Arbeitsmarktmonitor, a panel study that ceased in 1994. Another feature of both papers is that their approach to handle selection effects (ie. identify the causal effects of PEPs) is a parametric one. Hence, these studies are subject to the doubts raised in the econometric evaluation literature whether choosing more or less arbitrary parametric assumptions is the best way to identify the programme effects.

\footnotetext{
1 Many evaluations of active labour market policies have been conducted in the USA (see for example the surveys of Heckman, LaLonde, and Smith 1999, Heckman, Lochner, Smith, and Taber 1998, or LaLonde, 1995). However, the results are not comparable to the results of our study because of different institutional settings in the US labour market as well as different programme designs. Furthermore, in many cases data from social experiments are used. Such data is not available for Germany.
} 
In his research on employment policy in East Germany Hübler (1997) evaluates also the effects of PEP participation on individual unemployment probabilities. Among the several approaches used, including a multinominal logit model and a random effects probit model combined with different methods to control for selective programme participation, the method closest to our approach is to control for the selectivity by selecting the individuals for the nontreatment sample based on a distance measure in observable variables between treatment and non-treatment observations. The decision to stop the reduction of the non-treatment sample is based on a pre-programme-test similar to the one suggested by Heckman and Hotz (1989). The random effects probit model with the reduced sample is then used to estimate the programme effects. The results for the effects of PEP participation differ for the various specifications, but Hübler concludes that overall PEP participation does not create the expected positive effects.

An example of a study in a European setting that is more in the spirit of nonparametric identification of treatment (PEP) effects is a paper by Cockx and Ridder (1996). They discuss the effects of a wage subsidy for social security recipients on employment in Belgium. They argue that special institutional settings lead to a natural experiment, which is used to control for selection bias. They find that controlling for selection bias is important and reverses their results towards a negative, however insignificant, effect, that is a prolonged welfare participation.

An example for the evaluation of ALMPs in a transition economy is the study by Puhani (1999). He estimates the effects of several ALMPs in Poland, including training and PEPs, using among other methods a nonparametric approach based on the conditional independence assumption (CIA) and a matching estimator. Overall, with respect to individual unemployment, the effects found for participation in training are positive, while participation in PEPs and other subsidised job schemes cause an increase of unemployment. 
Although the above mentioned nonparametric approaches cannot be used given the institutional settings in East Germany and the data at hand, we use other nonparametric assumptions to identify the causal effects of PEP participation. The key issue to identify the causal effects of PEPs is to eliminate the effect of selective participation by the individuals. Since our data is not sufficiently informative to make the assumption that selection is only driven by observable variables (CIA) plausible, we base our analysis on an identifying strategy suggested by Heckman, Ichimura, and Todd (1997). They propose to use comparisons between participants and selected groups of non-participants as well as differencing over time to eliminate selection bias. Because in our case individuals start PEPs at different dates, we extend their approach and combine it with a particular matching approach by Lechner (1999).

The dataset available for this study is the Arbeitsmarktmonitor Sachsen-Anhalt, a panel based on the population of the state of Sachsen-Anhalt. Although the data has some drawbacks, it is in our opinion currently the best data available for evaluating PEPs in (a part of) East Germany. Therefore, we restrict our analysis to that state.

The results show a significant and substantial reduction of unemployment due to participation in a PEP after the PEP ended. This finding is fairly robust with respect to several specifications and different subpopulations. Interestingly, for men this is due to an higher employment probability, while for women the probability to drop out of the labour force increases.

The following section of the paper consists of a discussion of PEPs in East Germany and in Sachsen-Anhalt. Section 3 provides information on the institutional regulation of PEPs. Section 4 provides information on the data used in this study. The discussion of the econometric methods is contained in Section 5. Section 6 presents the results and Section 7 
concludes. Several appendices contain more information on the data and the estimation methods as well as some additional results.

\section{$2 \quad$ Stylized Facts}

\subsection{The Labour Market}

In 1990, the economy of East Germany was not prepared for unification and the resulting changes in institutional settings and relative prices. The sudden switch to a market economy and increasing wages brought huge changes in the labour market with worker displacement and rapidly decreasing labour demand. In reaction to these developments the government together with the labour offices set up large labour market programmes. The major components are short time working (Kurzarbeit, STW), ${ }^{2}$ early retirement (ER), continuous training and retraining (CTRT), and public employment programmes (Arbeitsbeschaffungsmassnahmen, PEPs). According to the number of participants as well as to the amount of money spent, ER and STW were the most important programmes in 1990 and 1991. From 1992 on, CTRT and PEPs replaced most of STW. ER remained important but the number of participants decreased slowly because no new participants were accepted. With some 'ups' and 'downs', partly due to financial restrictions, CTRT and PEPs are still important programmes of the active labour market policy in 1998.

The labour force of the German Democratic Republic (GDR) amounted to 9.7 million in 1989. In 1992, only 5.6 million people were regularly employed in East Germany, a drop of $40 \% .^{3}$ After 1992, the number of employed persons increased but remained below 6 million. In 1991 and 1992, the majority of people leaving regular employment went into some kind of active labour market policy programme, but unemployment rose sharply as well. In 1992,

\footnotetext{
2 In case of a temporary reduction of output a company can introduce STW. Employees work a reduced number of hours. The resulting income loss is partially made up by payments from the labour office.

3 This number does not include participants in the active labour market policy.
} 
more than one third (1996: nearly 30\%) of the total labour force was financed by the labour offices either through unemployment benefits or active labour market policy. Focusing on the active labour market policy alone, the labour offices spent 32 billion DM in 1992 in East Germany (1996: 16 billion DM).

Some time was needed to set up PEPs, but in 1992 an average of 400.000 people were employed in PEPs. Due to policy changes and financial restrictions, PEP participation decreased thereafter - as did participation in active labour market policies in general - to a level of between 235.000 and 315.000 persons. In total more than 2 million people participated in PEPs between 1991 and 1997, and more than 40 billion DM were spent. Although there might be some differences between the states in East Germany, the general picture drawn in this section is true for Sachsen-Anhalt as well.

\subsection{Sachsen-Anhalt}

Sachsen-Anhalt is one of the new federal states, located south-west of Berlin, joining borders with several other new federal states as well as with West Germany, but not with Berlin. A rough sketch of the economic structure before unification shows an industrialised south with a focus on chemical industry, coal mining and energy, and an agricultural northern part. Table 1 provides some information about the economy of Sachsen-Anhalt compared to the average of the economies of the new federal states and the West German average.

Table 1 shows that the economic development in Sachsen-Anhalt from 1991 to 1997 was somewhat worse than the average development in the new federal states. The share of the GDP in the new federal states produced in Sachsen-Anhalt decreased slightly over time. This development is reflected in the unemployment rate as well. Actually the unemployment rate in Sachsen-Anhalt was the worst in all new federal states in 1997. But the worse economic situation in Sachsen-Anhalt is not reflected in a corresponding higher share of PEP 
participants in Sachsen-Anhalt. Vice versa, the share of PEPs in Sachsen-Anhalt declines over time compared to the rest of East Germany.

Table 1: Comparing Sachsen-Anhalt with the New Federal States

\begin{tabular}{|c|c|c|c|c|c|c|c|c|c|c|}
\hline & \multicolumn{5}{|c|}{ GDP } & \multirow{2}{*}{\multicolumn{2}{|c|}{$\begin{array}{l}\text { Unemployment } \\
\text { (in \%) }\end{array}$}} & \multirow{2}{*}{\multicolumn{3}{|c|}{$\begin{array}{l}\text { Participants in PEPsc) } \\
\text { Total }\end{array}$}} \\
\hline & & Total & & & $\mathrm{ad}^{\mathrm{db}) c}$ & & & & & \\
\hline & $S A^{a)}$ & NFS a) & $\begin{array}{l}\text { SA in } \% \\
\text { of NFS }\end{array}$ & SA & NFS & SA & NFS & SA & NFS & $\begin{array}{l}\text { SA in \% } \\
\text { of NFS }\end{array}$ \\
\hline 1991 & 36 & 206 & $18 \%$ & 19 & 19 & 10 & n.a. & 35 & 183 & $19 \%$ \\
\hline 1992 & 46 & 263 & $18 \%$ & 24 & 25 & 15 & 15 & 88 & 388 & $23 \%$ \\
\hline 1993 & 55 & 305 & $18 \%$ & 29 & 29 & 17 & 16 & n.a. & 250 & n.a. \\
\hline 1994 & 61 & 355 & $17 \%$ & 32 & 33 & 18 & 16 & 61 & 280 & $22 \%$ \\
\hline 1995 & 64 & 381 & $17 \%$ & 34 & 36 & 17 & 15 & 64 & 312 & $21 \%$ \\
\hline 1996 & 66 & 397 & $17 \%$ & 35 & 37 & 19 & 17 & 58 & 277 & $21 \%$ \\
\hline 1997 & 70 & 422 & $17 \%$ & 37 & 39 & 22 & 18 & n.a. & 234 & n.a. \\
\hline
\end{tabular}

Sources: Statistisches Jahrbuch für die Bundesrepublik Deutschland, several issues; several special issues Zeitreihen für ausgewählte Arbeitsmarktindikatoren, Landesarbeitsamt Sachsen-Anhalt/Thüringen; ANBA (Amtliche Nachrichten der Bundesanstalt für Arbeit), several issues; Arbeitsmarkt in Zahlen: Arbeitsbeschaffungsmaßnahmen, Berichtsmonat September 1998, Bundesanstalt für Arbeit, Table 1, 2; Arbeitsmarkt in Zahlen: aktuelle Zahlen, September 1998, Bundesanstalt für Arbeit, p. 52; Institut für Arbeitsmarkt- und Berufsforschung, Zahlenfiebel 1995, Table 7.2; Statistisches Jahrbuch des Landes Sachsen-Anhalt 1997; information from IWH Halle Juli 1998.

Notes: $\quad$ SA ... Sachsen-Anhalt; NFS ... all new federal states (incl. East Berlin and Sachsen-Anhalt). 1.9 million people live in SA, $18 \%$ of the population of the NFS.

See Section 3 for a definition of different kinds of PEPs and what is summarized in PEPs within this paper. n.a.: not available.
a) In billion DM.
b) In relation to population of age 15 to 65 (for NFS without East Berlin).
c) In thousands.

\subsection{PEP Participation}

The following Tables 2 and 3 provide some data on PEP participation in East Germany and, if available, for Sachsen-Anhalt separately. ${ }^{4}$

The use of PEPs reached a peak as early as in 1992. But PEPs kept to be an important part of ALMPs in the following years as can be seen from the expenditures as well as the participation. From 1992 to 1996 some tendency to increase the average PEP duration is found when comparing the inflows and the average stocks. A rising share of women in PEPs reflects the unfavourable development on the labour market for women in East Germany as

\footnotetext{
4 Further information and data about the East German labour market in general and PEP in particular can for example be found in Wolfinger $(1994,1995)$ or Spitznagel (1993).
} 
well as an increasing focus of the labour offices towards persons with special labour market problems. In general the pattern is the same for Sachsen-Anhalt.

Table 2: Expenditures on PEPs by the Labour Offices

\begin{tabular}{lccrrrr}
\hline \hline & & NFS & & & \multicolumn{2}{c}{ SA } \\
& Total & PEPa) & $\$ 249 h^{\text {b) }}$ & Total & PEPa) & §249h ${ }^{\text {b) }}$ \\
\hline 1991 & 3,075 & 3,075 & -- & 612 & 612 & --- \\
1992 & 5,083 & 5,083 & -- & 1,664 & 1,664 & --- \\
1993 & 6,905 & 6,811 & 94 & 1,388 & 1,359 & 29 \\
1994 & 4,722 & 3,397 & 1,325 & 1,680 & 1,359 & 321 \\
1995 & 7,109 & 5,832 & 1,277 & 1,734 & 1,416 & 318 \\
1996 & 8,156 & 6,835 & 1,321 & 1,701 & 1,422 & 279 \\
$1997^{c)}$ & 6,703 & 5,322 & 1,381 & 1,422 & 1,136 & 286 \\
\hline
\end{tabular}

Source: ANBA, several issues.

Notes: In million DM per year; SA ... Sachsen-Anhalt; NFS ... all new federal states (incl. East Berlin and Sachsen-Anhalt). See Section 3 for a definition of different kinds of PEPs and what is summarized in PEPs within this paper.
a) Regular PEP only.
b) §249h was introduced in 1993.
c) Since September 1997 data include West Berlin.

Table 3: Participants in PEPs

\begin{tabular}{|c|c|c|c|c|c|c|c|c|c|c|c|c|}
\hline \multirow[b]{4}{*}{ Year } & \multicolumn{6}{|c|}{ In East Germany } & \multicolumn{6}{|c|}{ In Sachsen-Anhalt } \\
\hline & \multirow{2}{*}{\multicolumn{2}{|c|}{$\begin{array}{c}\text { Inflow } \\
\text { in PEPs } \\
\text { Original PEP }\end{array}$}} & \multicolumn{4}{|c|}{$\begin{array}{l}\text { Average of persons } \\
\text { employed in PEPs }\end{array}$} & \multirow{2}{*}{\multicolumn{2}{|c|}{$\begin{array}{c}\text { Inflow } \\
\text { in PEPs } \\
\text { Original PEP }\end{array}$}} & \multicolumn{4}{|c|}{$\begin{array}{l}\text { Average of persons } \\
\text { employed in PEPs }\end{array}$} \\
\hline & & & \multicolumn{2}{|c|}{ Original PEP } & \multicolumn{2}{|c|}{$\S 249 \mathrm{~h}$} & & & Origir & nal PEP & & $249 h$ \\
\hline & Total & $\begin{array}{l}\text { Thereof } \\
\text { women }\end{array}$ & Total & $\begin{array}{l}\text { Thereof } \\
\text { women }\end{array}$ & Total & $\begin{array}{l}\text { Thereof } \\
\text { women }\end{array}$ & Total & $\begin{array}{l}\text { Thereof } \\
\text { women }\end{array}$ & Total & $\begin{array}{l}\text { Thereof } \\
\text { women }\end{array}$ & Total & $\begin{array}{l}\text { Thereof } \\
\text { women }\end{array}$ \\
\hline 1991 & 422 & $37 \%$ & 183 & $36 \%$ & 0 & --- & n.a. & n.a. & 35 & n.a. & 0 & --- \\
\hline 1992 & 296 & $44 \%$ & 388 & $41 \%$ & 0 & --- & 59 & n.a. & 88 & n.a. & 0 & --- \\
\hline 1993 & 243 & $53 \%$ & 237 & $48 \%$ & 23 & n.a. & 51 & $51 \%$ & 50 & $44 \%$ & n.a. & n.a. \\
\hline 1994 & 293 & $60 \%$ & 192 & $60 \%$ & 88 & $36 \%$ & 58 & n.a. & 40 & $62 \%$ & 21 & $33 \%$ \\
\hline 1995 & 222 & $63 \%$ & 206 & $65 \%$ & 106 & $39 \%$ & 43 & n.a. & 41 & $69 \%$ & 23 & $33 \%$ \\
\hline 1996 & 235 & $62 \%$ & 191 & $65 \%$ & 86 & $43 \%$ & 50 & n.a. & 40 & $66 \%$ & 18 & $39 \%$ \\
\hline 1997a) & 142 & $58 \%$ & 154 & $64 \%$ & 80 & $44 \%$ & n.a. & n.a. & 33 & n.a. & n.a. & n.a. \\
\hline
\end{tabular}

Source: ANBA, several issues; Arbeitsmarkt in Zahlen: Arbeitsbeschaffungsmaßnahmen, Berichtsmonat September 1998, Bundesanstalt für Arbeit, Table 1, 2; Arbeitsmarkt in Zahlen: aktuelle Zahlen, September 1998, Bundesanstalt für Arbeit, p. 52; Institut für Arbeitsmarkt- und Berufsforschung, Zahlenfiebel 1995, Table 7.2; Statistischer Bericht A VI 7 i/96 des Stat. Landesamts Sachsen-Anhalt, 1996: Table 14, 15, 1994: Table 8, 9, 1995: Table 14, 15, 1993: Table 9; Statistisches Jahrbuch des Landes Sachsen-Anhalt 1997; information from IWH Halle Juli 1998.

Notes: $\quad$ In 1000 persons.

See Section 3 for a definition of different kinds of PEPs and what is summarized in PEPs within this paper. n.a.: not available.

a) Since July 1997 East Germany includes West Berlin.

The type of work a person has to perform in a PEP could be expected to influence the employment chances on the regular labour market. Although there is no direct data available on the type of work, data on the sector in which the PEP is active shows the following picture. 
More than half of all participants in PEPs are in sectors like agriculture, infrastructure, building, site development, landscape building and environmental redevelopment. The share of PEPs in these sectors rises from 53\% in 1992 to $62 \%$ in 1993 and decreases slowly to 50\% in 1997. PEPs in social services steadily increase their share from $13 \%$ in 1992 to about $22 \%$ in 1997. Constant over time about $8 \%$ of all PEP are of an administrative kind, and for the remaining PEPs no information is available.

Although complete statistics appear not to be available there are some hints that PEPs in Sachsen-Anhalt differ from the average of all new federal states. Emmerich $(1993$, p. 6) states that in 1991/1992 11\% of PEP participants are employed in so-called Mega-PEP, while this number is $21 \%$ in Sachsen-Anhalt. ${ }^{5}$ Furthermore, all new federal states spend additional money on Mega-PEPs, but four fifths of the total amount in 1991/92 came from Sachsen-Anhalt (Emmerich, 1993, Table 7 and 8). Brinkmann and Wolfinger (1994, p. 17 and tables) show that in the second quarter of 1994 only 7\% of all PEPs according to $\$ 249 \mathrm{~h}$ take place in Sachsen-Anhalt, but they employ $25 \%$ of all participants in such PEPs. ${ }^{6}$ Furthermore, there is a sectoral concentration of Mega-PEPs in Sachsen-Anhalt in coal mining, the chemical industry and steel as well as a corresponding regional concentration.

\section{Institutional Arrangements for PEPs in East Germany}

In early 1990 the German Democratic Republic (GDR) adopted a labour law by and large similar to the West German one, the Arbeitsförderungsgesetz (AFG). After unification the West German AFG came into force in East Germany as well, although many exemptions were added. The AFG contains several regulations on PEPs. ${ }^{7}$ Here we will discuss PEPs according

\footnotetext{
Mega-PEPs get unusual high subsidies from the labour offices. They usually employ a higher number of persons, and typically the good or service produced is more like investment than consumption compared to the average PEP, e.g. by providing new infrastructure or by cleaning industrial sites (Emmerich, 1993, p. 6).

6 PEP according to $\$ 249 \mathrm{~h}$ is a somewhat different kind of PEP in East Germany, introduced in 1993. See Section 3 for more information on different kinds of PEPs in East Germany.

7 The information given in this section draws on formal sources like laws as well as on informal sources, which are important to catch effects of the daily implementation as well as the use of exceptions. The major informal
} 
to §§91-96 AFG (Arbeitsbeschaffungsmassnahmen) and PEPs according to §249h AFG (Produktive Lohnkostenzuschüsse Ost), which were introduced in January $1993 .^{8}$ In most aspects relevant for this study both programmes are similar, in formal terms as well as in informal handling. Furthermore, our data does not allow a separation. Therefore, throughout this paper, the phrase public employment programme (PEP) includes both types of PEPs if not stated otherwise.

Participants in a PEP are not directly employed or paid by the labour office. Rather they have a regular employment contract with a programme supporting employer (PSE, a public institution, a private nonprofit organisation, or a firm) which automatically ends with the end of the PEP. The labour offices reimburse the PSE for a part or all of the wage paid. ${ }^{9}$ The jobs subsidised in a PEP must not replace existing jobs. The work done in the programme must be useful to the public and would not be done without the PEP. ${ }^{10}$

To control for selection bias it is important to know how a PEP is created and why an individual participates. In practice, there were at least three different possibilities PEPs were created in East Germany, although a sharp separation is not possible.

First, a company or a part of a company was to be closed. To avoid mass layoffs, the whole company or a part of it was transferred to a PEP. The decision about individual PEP

source were interviews we conducted in East German labour offices in 1996 and 1997. The interviews were partly questionnaire-led, partly free conversation held in local labour offices and the Landesarbeitsämter, the regional head offices. Although there were no interviews in Sachsen-Anhalt, we expect the general results to be true for Sachsen-Anhalt as well.

For more (formal) information on the regulations see the AFG, the Sozialgesetzbuch III, and corresponding legislation on lower levels.

8 For convenience we use 'regular PEPs' and 'original PEPs' for PEPs according to $\S 91 \mathrm{ff}$ AFG and '\$249h' as a name for PEPs according to $\$ 249 \mathrm{~h}$ AFG. PEPs for older unemployed (Arbeitsbeschaffungsmassnahmen für ältere Arbeitnehmer, $\$ \$ 97-99$ AFG) are not discussed because the special target group for this measure, unemployed older than fifty-five, is excluded in this work.

9 Regularly between $50 \%$ and $75 \%$ of the wages are covered and in special cases up to $100 \%$, that appear to be common practise in East Germany. Furthermore, the labour office could cover the cost to set up a workplace or provide loans for that. The rules were tightened over time. After 1993 the labour office accepted only wages below $90 \%$ of the wage of a comparable unsubsidized job. For $\$ 249 \mathrm{~h}$ programmes the subsidy is based on the average unemployment benefits the labour office would have had to pay otherwise.

10 A delay that would occur without the PEP is sufficient as well. For $\$ 249 \mathrm{~h}$ there is a closed catalogue of types of work. 
participation was not based on individual considerations but exception regulations were used to transfer the workers into the PEP. Many programmes in 1991 and 1992 were of this kind.

Second, Arbeitsbeschaffungs- und Beschäftigungsgesellschaften (ABG) were used. ${ }^{11}$ They are set up by a regional or local government or a large company as a kind of 'counterpart' to the labour offices' active labour market policies. While the labour office takes care of the financing and supervision, the ABG creates, organizes, and administers the PEP. Furthermore, AGBs provide information and help for the participants. It is not clear, how the decisions about the participants are made and the requirements for individual participation are checked when an ABG creates a PEP. Some of the ABGs are closed for new participants, others are not.

Third, a PEP is created in the 'normal' way. Normal means according to the regulations of the labour law and the common use in West Germany. A future PSE proposes to create a PEP. If the labour office approves it, the labour office decides about the participants as well. ${ }^{12}$ Here, the individual requirements should usually be met.

It is not clear which of these forms is the most important, and there are - according to our knowledge - no complete statistics available on ABGs or the use of exceptions in the labour law. It seems that the third possibility was typical for smaller PEPs with only a few employees while PEPs created through the other ways typically employ many people. Unfortunately, our data do not provide any information on the way a PEP is created.

The most important formal requirement for participating in a PEP is that the individual is unemployed and entitled to some kind of unemployment payments (or social assistance since 1994) right before participating in a PEP. Furthermore, the person must have been

\footnotetext{
11 Many different names are used for this kind of companies.

12 In the interviews, people deciding about PEP participation in the labour offices pointed out that neither the employer nor the individual participant has any influence on the participation decision.
} 
unemployed for at least six months within the last twelve months. ${ }^{13}$ People with special difficulties on the labour market are preferred. Those are the disabled, the unemployed older than fifty, persons below twenty-five without a vocational degree, the long term unemployed and - a special regulation for East Germany - women. The labour office can depart from all formal requirements for social or labour market reasons.

Typically a PEP is limited to twelve months although every other - longer or shorter - length up to twenty-four months, under special conditions even thirty-six months, is possible. During the PEP people get paid the Tariflohn, which is in almost all cases higher than unemployment benefits. ${ }^{14}$ Beginning in 1994, this was subsequently lowered to $90 \%$ of the Tariflohn, but private firms in East Germany often pay less than the Tariflohn as well and this did not increase the incentive to leave PEP much. Furthermore, during PEP social security contributions are paid, which could create new rights for unemployment benefits.

An individual leaves a PEP when the PEP ends. It is possible - and hoped for - that the PSE employs the participant without subsidy after the PEP. Furthermore, an individual must leave a PEP immediately to take up a job offer on the regular labour market or for a training programme proposed by the labour office. The labour office as well as the participant are required to search for such possibilities during PEP.

${ }^{13}$ For $\$ 249 \mathrm{~h}$ regulations are somewhat less tight. Only three months of unemployment within the last six months are required. Alternatively, being in a regular PEP or in STW (13 or more weeks with 10 or less \% working time) is sufficient as well.

14 Tariflohn is the wage rate trade unions and employers agreed on in regional and sectoral specific contracts. Unemployment benefits in Germany range from 53 to $68 \%$ of the former net income, depending on family status and duration of unemployment. The rates change over time. Therefore, with the exception of a wage rate for the PEP employment being much lower than the former personal wage, there is a financial incentive to participate in PEPs. 


\section{Data}

\subsection{The Arbeitsmarktmonitor Sachsen-Anhalt}

The Arbeitsmarktmonitor Sachsen-Anhalt (AMM-SA) was primarily designed to provide information about the current situation of the labour market in Sachsen-Anhalt. ${ }^{15}$ Creating a (panel) data set for scientific use is only a secondary goal. It contains a wide variety of questions including the labour market status now and a year ago, information about the job position and the employer, participation in active labour market policies, earnings, education, family and living, and personal opinions about political and labour market issues.

The AMM-SA is compiled from questionnaires mailed to individuals of age 15 to 65 living in the federal state of Sachsen-Anhalt. The first series of interviews took place in March 1992, and from autumn 1992 on, it has been repeated every year. We use data up to the wave of autumn 1997. For each interview, between 10,000 and more than 20,000 questionnaires were mailed out, resulting in 6,000 to 10,000 available observations, equal to 0.3 to $0.5 \%$ of the population. Of these between 500 and 1,000 of the observations in each wave have experience with PEPs. The general structure of the data is a mixture of cross-section and panel. Wave one and two are a panel, but for wave three a new cross-section was drawn. From wave four on, in every wave previously interviewed as well as newly drawn individuals are included. Panel mortality in the data is high. For example, of 9,252 persons participating in autumn 1993 only 1,268 persons $(14 \%)$ have a valid interview in $1997 .{ }^{16}$ Difficulties when using the panel structure apart from the panel mortality arise from different definitions of the variables in the questionnaire over time and from not including all questions in all questionnaires. Nevertheless, for our study we consider the AMM-SA the best data currently available on

\footnotetext{
15 More information on the AMM-SA can for example be found in Wiener (1995) or in Zentrum für Sozialforschung (1998; pages 11-15, 18-20, and in the last appendix).

16 The dropout of 535 is explained by the age restriction, for the remaining 8,717 dropouts no information is available. It could be 'correct' dropouts (e.g. the person died), but it has to be assumed that the major reason is non-respons. No detailed non-response-study is available, but we could not find any substantial (unplanned) changes in the composition of the samples, neither through the panel mortality nor through our selection rules (see below).
} 
PEPs in East Germany. Table 14 in Appendix A provides an overview of the variables used in this study.

\subsection{Selection Rules and Descriptive Statistics}

For people starting their working live by participating in a PEP the effects of a PEP might be quite different than for people in the middle of their working life. Therefore our sample is restricted to persons who were at least 22 years old in 1993. Furthermore, this restriction allows us to use schooling as time-constant variable in the estimation. If the first available observation is at age 55 or older, the person is deleted to avoid catching effects of early retirement. Participants in PEP of age 52 or older at the start date of PEP are excluded, because PEPs were used for older unemployed to 'bridge' the time to early retirement. Our interviews at the labour offices confirmed that. Under these circumstances the purpose is not to increase the employment prospects of the participants.

Further exclusions are made because of data limitations. Due to missing answers or limitations of the questionnaire, for some PEP participants neither the start nor the end date of the PEP is known. They are excluded. Because of low numbers of cases or inconsistent information observations with certain characteristics were deleted from the sample. Table 13 in Appendix A presents more details on the selection and the numbers of observations in the sample before and after selection. In addition we exclude persons with missing information in relevant questions for every estimation step separately.

In the sample of people not participating in PEPs, no further persons had to be excluded because they were not eligible for PEP. Due to the exemption rules for PEP participation in East Germany all persons could have participated in PEP, although the probabilities for participation differ substantially.

The distribution of start and end dates for PEPs in our sample is not uniform (see Table 4 as well as Figure 4 in Appendix A). We observe start dates between November 1989 and 
September 1997 in the original data set, but the selection rules applied restrict the observations to start a PEP between April 1991 and September 1997. The median of start dates in the restricted sample is January 1992, and 65\% of all PEPs start before September 1992. The median of end dates is June 1993, 60\% of PEP participation ended between September 1991 and August 1993. Partly, this reflects the pattern of PEP participation in East Germany as described above. But the distribution is also driven by the unbalanced panel design of the sample with different sample sizes in each year, and the designs of the questionnaires. $^{17}$

Table 4: Statistics for the Start and End Dates of PEP and the Duration in the Sample

\begin{tabular}{lccc}
\hline \hline & Start of PEP (date) & End of PEP (date) & Duration of PEP (months) \\
\hline Mean & October 1992 & November 1993 & 14.8 \\
$10^{\text {th }}$ percentile & June 1991 & February 1992 & 3 \\
$25^{\text {th }}$ percentile & August 1991 & July 1992 & 6 \\
Median in sample & January 1992 & June 1993 & 12 \\
$75^{\text {th }}$ percentile & November 1993 & July 1995 & 20 \\
$90^{\text {th }}$ percentile & August 1995 & August 1996 & 30 \\
\hline Number of observations & 1123 & 778 & 778 \\
\hline
\end{tabular}

Source: Own calculations.

Notes: Sample similar to the sample used to estimate the partial propensity score.

A typically PEP duration is twelve months, and the regular maximum is twenty-four months. Table 4 and Figure 1 confirm this, with $17 \%$ of all PEPs ending after twelve months and only very few lasting longer than twenty-four months. ${ }^{18}$ The mean of the PEP participation in the sample is 14.8 months, the median 12 months. Of all PEPs in the sample $10 \%$ have a duration of less than or equal to three months (six months: $25 \%$; twelve months: $65 \%$; twenty-four months: $89 \%$ ). For some observations in the sample PEP participation is right censored. Only a small fraction of these persons is still in PEP in September 1997, while most of the censoring is due either to panel attrition or to insufficient information in the questionnaires.

\footnotetext{
${ }^{17}$ No complete information on start and end dates of PEP are available for September 1994 and 1995, while in September 1993 and 1996 questions about the complete PEP history along with dates were included, although no more than one spell was allowed.

${ }^{18}$ Actually there are even more shorter PEP spells because 'start date' is coded as the first known start date and 'end date' as the last known end date. There are multiple PEP spells, but the data available only allows the identification of some of them.
} 
These observations could not be used for the final evaluation, but provided useful information for the estimation of the propensity score.

Figure 1: Duration of Individual PEPs

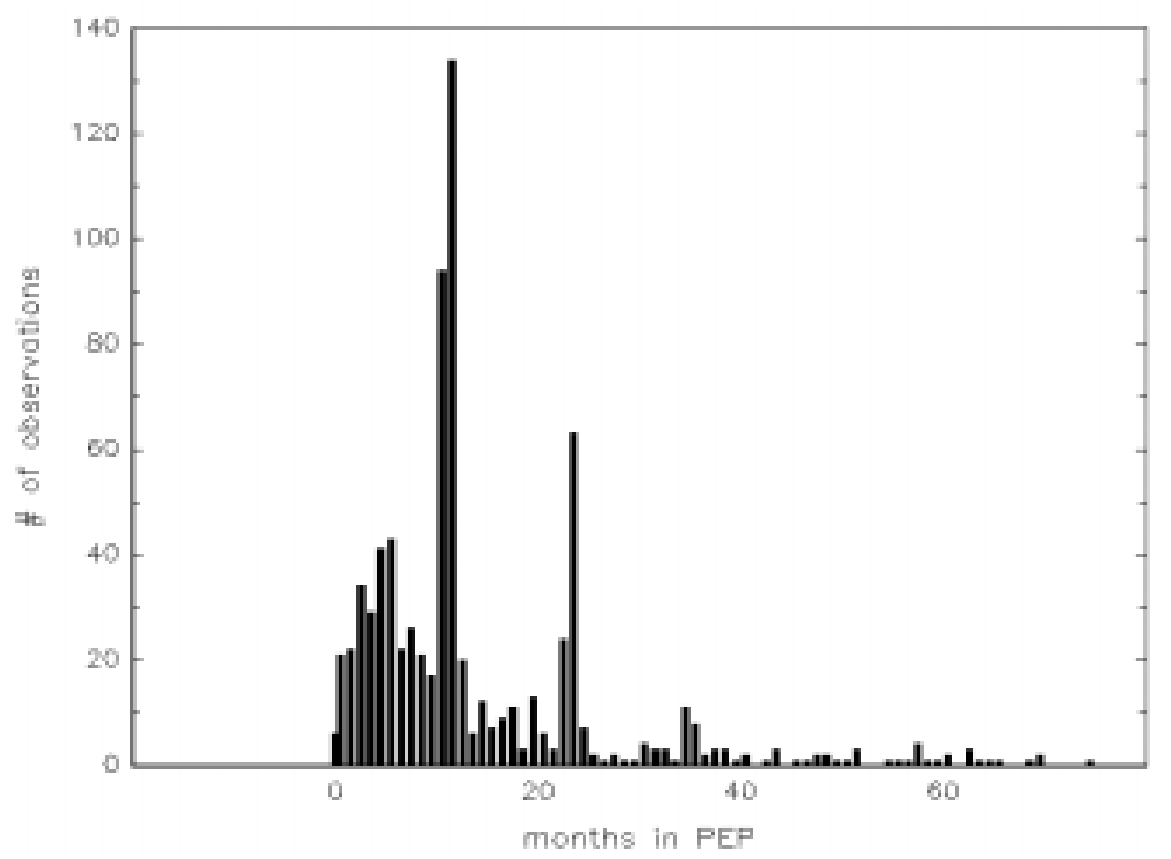

Note: $\quad$ X-axis: Time, measured in months ; Y-axis: number of observations. Long PEP duration might reflect multiple PEP participation (identification in the data not possible). The questionnaire was designed in a way that it is possible to answer either eleven or twelve months for a full year of PEP participation depending on the individual understanding. Number of valid observations: 778.

Splitting the sample in two groups, one with PEP participants and one with non-participants, we find some differences between them. Table 5 shows that people with a higher degree of formal education are less likely to participate in PEPs. The same pattern appears when comparing the groups according to the level of formal job education or the last known job position. Not surprisingly unemployment is higher among PEPs participants. 


\begin{tabular}{|c|c|c|}
\hline & \multicolumn{2}{|c|}{$\begin{array}{c}\text { Mean in subsample or } \\
\text { share in subsample in \% }\end{array}$} \\
\hline Age (1993) & 38.5 years & 38.8 years \\
\hline Gender. Female & 52 & 52 \\
\hline \multicolumn{3}{|l|}{ Schooling: Highest degree } \\
\hline University entrance degree (Abitur) & 28 & 23 \\
\hline Medium (Klasse 10) & 54 & 54 \\
\hline Low (Klasse 9) & 18 & 22 \\
\hline University degree & 18 & 15 \\
\hline \multicolumn{3}{|c|}{ Unemployment: Registered as unemployed in } \\
\hline March 1991 & 6 & 16 \\
\hline September 1992 & 10 & 15 \\
\hline September 1994 & 9 & 25 \\
\hline September 1996 & 10 & 30 \\
\hline September 1997 & 11 & 42 \\
\hline Unemployment rate in region (mean)a) & 21 & 22 \\
\hline PEP rate in region $(\text { mean })^{b}$ & 4 & 4 \\
\hline \multicolumn{3}{|l|}{ Living in } \\
\hline City of Dessau & 4 & 2 \\
\hline City of Halle & 12 & 5 \\
\hline City of Magdeburg & 11 & 8 \\
\hline Area of Aschersleben-Straßfurt & 4 & 6 \\
\hline Area of Anhalt-Zerbst & 3 & 3 \\
\hline Area of Bitterfeld & 4 & 7 \\
\hline Area of Bördekreis & 3 & 3 \\
\hline Area of Quedlinburg & 3 & 6 \\
\hline Area of Wernigerode & 4 & 3 \\
\hline Max. number of observations & 12,565 & 1,123 \\
\hline
\end{tabular}

Note: $\quad$ Some statistics are generated with less observations because of missing information. See Table 14 in Appendix A for the definitions of the variables.

a) Mean over time (91-97) of unemployment rates in 8 regions in Sachsen-Anhalt weighted according to the respective regional distribution.

b) Mean over time (91-97) of PEP participation rates in 8 regions in Sachsen-Anhalt weighted according to the respective regional distribution.

\section{Econometric Methodology and Empirical Implementation}

\subsection{The Causality Framework and the Targets of the Evaluation}

The empirical analysis tries to answer questions like "What is the average gain for PEP participants compared to the hypothetical state of non-participation?" This is the so-called treatment effect on the treated. The underlying notion of causality requires the researcher to determine whether participation or non-participation in PEPs has an effect on the respective 
outcomes, such as earnings or employment status. ${ }^{19}$ Therefore, the framework that serves as a guideline for the empirical analysis is the potential-outcome approach to causality suggested by Roy (1951) and Rubin (1974).

To facilitate the discussion, the following notation is useful. $Y^{p}$ and $Y^{n}$ denote the potential outcomes ( $p$ denotes participation in treatment, i.e. PEP, $n$ no PEP).$^{20}$ Additionally, denote variables that are unaffected by treatment - called attributes by Holland (1986) - by X. It remains to define a PEP participation indicator $S$, that determines whether person $i$ participates in a $\operatorname{PEP}\left(s_{i}=1\right)$ or not $\left(s_{i}=0\right)$. The observable outcome is $y_{i}=s_{i} y_{i}^{p}+\left(1-s_{i}\right) y_{i}^{n}$. Hence, the causal effect, for example defined as the difference of two potential outcomes, can never be estimated, because the counterfactual $\left(y_{i}^{p}, s_{i}=0\right)$ or $\left(y_{i}^{n}, s_{i}=1\right)$ to the observable outcome $y_{i}$ is unobservable. However, the quantity of interest to answer the question placed on the beginning of this section is the average causal effect of PEPs for PEP participants $\theta_{0}:{ }^{21}$

$\theta_{0}:=E\left(Y^{p}-Y^{n} \mid S=1\right)=E\left(Y^{p} \mid S=1\right)-E\left(Y^{n} \mid S=1\right)=g^{p}-E\left(Y^{n} \mid S=1\right)$.

$g^{p}$ can be consistently estimated by the sample mean of $y_{i}$ in the subsample of PEP participants. ${ }^{22}$ The problem is the term $E\left(Y^{n} \mid S=1\right)$. Much of the literature on causal models in statistics and selectivity models in econometrics is devoted finding useful identifying assumptions to predict the unobserved expected nontreatment outcomes of the treated

${ }^{19}$ See Holland (1986) and Sobel (1994) for an extensive discussion of concepts of causality in statistics, econometrics, and other fields.

${ }^{20}$ As a notational convention capital letters indicate quantities of the population or of members of the population and lower case letters denote the respective quantities in the sample. The units of the sample $(i=1, \ldots, N)$ are assumed to be the result of $N$ independent draws from this population.

${ }^{21} E(\mid S=1)$ denotes the mean of the respective random variables in the population of PEP participants.

${ }^{22}$ Note that in the application we will estimate a slightly different parameter because due to some nonrepresentiveness of the sample and due to our selection rules explained in the previous section, the distribution of participants in the population and in the sample could be somewhat different. 
population by using the observable nontreatment outcomes of the untreated population $\left(y_{i}^{n}, s_{i}=0\right)$ in different ways. ${ }^{23}$

\section{$5.2 \quad$ Identifying Restrictions}

\subsubsection{Conditional Independence Assumption}

The so-called conditional independence assumption (CIA; Rubin, 1977) can be used to identify $E\left(Y^{n} \mid S=1\right)$ :

$Y^{n} \amalg S \mid X=x, \forall x \in \chi$

CIA means that participation is independent (Ш) of the non-treatment outcome conditional on the values of covariates or attributes $x$ in the space $\chi$. Thus $E\left(Y^{n} \mid S=1, X=x\right)=$ $E\left(Y^{n} \mid S=0, X=x\right)$, and $\theta_{0}$ is identified. Compared to model-based econometric approaches, CIA allows one to estimate treatment effects directly without imposing functional form or parametric assumptions that are often imposed when estimating a structural model. Subsequently, we will denote by $\theta_{0}^{C I A}$ the limit of an estimator that is consistent under the CIA assumption $\left(\underset{N \rightarrow \infty}{p \lim } \hat{\theta}_{N}^{C I A}=\theta_{0}^{C I A}\right)$ :

$\theta_{0}^{C I A}=E\left(Y^{p} \mid S=1\right)-E_{X}\left[E\left(Y^{n} \mid S=0, X=x\right) \mid S=1\right]=g^{p}-E_{X}\left[g^{n}(x) \mid S=1\right]$

$g^{p}=E\left(Y^{p} \mid S=1\right) ; \quad g^{n}(x):=E\left(Y^{n} \mid X=x, S=0\right)$.

To justify CIA, the important task is to identify and observe all variables that could be mutually correlated with assignment and potential nontreatment outcomes. This implies that there is no important variable left out that influences nontreatment outcomes as well as

\footnotetext{
${ }^{23}$ This may include the outcomes of participants prior to PEP.
} 
assignment given a value of the relevant attributes. For this study the reasoning in the previous section suggests that $X$ should include information on schooling, job training and experience, the complete labour market history of the person and individual socio-economic characteristics.

It is thus obvious that in our case the validity of CIA requires a very informative data set. However, for PEPs in East Germany, such data is not (yet?) available. The data used in this study for Sachsen-Anhalt has several shortcomings. Employment histories are only available on a yearly basis. Any information on employment before or at unification is missing. Therefore we might miss employment dynamics in the month just before PEP participation. Since unemployment is one important selection criterion, this will invalidate CIA with our data. In addition to this, the considerable amount of panel attrition, the redrawing of the sample in 1993, and the refreshing of the sample thereafter results in a very unbalanced panel design. This leads to relatively short observation periods for many people.

A technical problem related to the choice of variables to be included in $X$ is the potential high dimension of $X$ that complicates the estimation of the conditional expectation. Let $P(x)=$ $P(S=1 \mid X=x)$ denote the propensity score that is defined as the nontrivial probability $(0<P(x)$ $<1)$ of being assigned to a PEP conditional on $X$. Furthermore, let $b(x)$ be a function of attributes such that $P[S=1 \mid b(x)]=P(x)$, i.e. the balancing score $b(x)$ is at least as 'fine' as the propensity score. If CIA is valid, Rosenbaum and Rubin (1983) show that $Y^{n} \amalg S \mid b(X)=b(x), \forall x \in \chi$ holds, hence:

$$
E\left(Y^{n} \mid S=1\right)=E_{X}\left\{E\left[Y^{n} \mid S=0, b(X)=b(x)\right] \mid S=1\right\} .
$$

The major advantage of this property is the reduction of the dimension of the estimation problem. The disadvantage is that the probability of assignment - and consequently any 
balancing scores that reduce the dimension of the estimation problem - is unknown and has to be estimated.

\subsubsection{The Conditional Bias Stability Assumption}

For the further discussion it is useful to introduce the time dimension explicitly as $Y=$ $\left\{Y_{-\mathrm{T}}, \ldots, Y_{-2}, Y_{-1}, Y_{1}, Y_{2}, \ldots, Y_{\mathrm{T}}\right\}, Y^{p}=\left\{Y_{-\mathrm{T}}^{p}, \ldots, Y_{-2}^{p}, Y_{-1}^{p}, Y_{1}^{p}, Y_{2}^{p}, \ldots, Y_{\mathrm{T}}^{p}\right\}$ and $Y^{n}=\left\{Y_{-\mathrm{T}}^{n}, \ldots, Y_{-2}^{n}, Y_{-1}^{n}\right.$, $\left.Y_{1}^{n}, Y_{2}^{n}, \ldots, Y_{\mathrm{T}}^{n}\right\}$. The period between -1 and 1 includes the time in PEP and may be longer than the other periods, in particular it varies individually. All other periods are equally spaced. $T, \ldots,-1$ and $1, \ldots, T$ refer to points in time where interviews take place, the assigned value depending on the distance to the begin and end of the individual PEP spell, respectively. This leads to the following re-definition of effect of the treatment on the treated in period $t$ :

$\theta_{t, 0}:=E\left(Y_{t}^{p}-Y_{t}^{n} \mid S=1\right)=E\left(Y_{t}^{p} \mid S=1\right)-E\left(Y_{t}^{n} \mid S=1\right)=g_{t}^{p}-E\left(Y_{t}^{n} \mid S=1\right), t=\ldots-1,1,2, \ldots .\left(1^{\prime}\right)$

In that framework treatment is defined as participation in a PEP some time in our observation period ( $S$ has no index referring to time). Therefore, we allow for a treatment effect before any participation in a treatment.

In a recent paper Heckman et al. (1997) propose a generalisation of CIA. This assumption could be applied when there is at least one observation of the outcome before a PEP and one observation after a PEP. The idea is that although CIA may not hold, it may be reasonable to assume that the bias due to an incorrectness of the CIA is the same for at least one date before a PEP $(\tau, \tau<0)$ and one date after a PEP $(t, t>0)$. If the true effect of a PEP is indeed zero for that date before the PEP, than an estimated treatment effect using CIA for period $\tau$ gives an estimate of the bias. This bias estimate could be used to correct the estimate of the treatment effect for the date after the PEP. 
To see these issues more clearly, let us introduce some additional notation. Equation

defines the average bias that occurs if CIA is not true: ${ }^{24}$

$B_{t}^{C I A}:=E_{X}\left[B_{t}^{C I A}\left(x_{t}\right) \mid S=1\right] ; \quad B_{t}^{C I A}\left(x_{t}\right):=E\left(Y_{t}^{n} \mid X=x_{t}, S=1\right)-g_{t}^{n}\left(x_{t}\right) ; \quad t=-T, \ldots, T$.

However, the validity of CIA implies that $g_{t}^{n}\left(x_{t}\right)=E\left(Y_{t}^{n} \mid X=x_{t}, S=1\right)$. Therefore, the bias should be zero point-wise in the $\chi$-space ( $\left.B_{t}^{C I A}\left(x_{t}\right)=0, \forall x_{t} \in \chi\right)$. If CIA does not hold, Heckman et al. (1997) suggest an alternative assumption that will be called the bias stability assumption (BSA) in the remainder of this paper:

$B_{t}^{C I A}\left(x_{t}\right)-B_{\tau}^{C I A}\left(x_{\tau}\right)=0$ for at least one pair $(\tau, t), \tau<0 ; t>0, \forall x \in \chi$

The quantity identified by BSA is defined as:

$\theta_{t-\tau, 0}^{B S A}=\theta_{t, 0}^{C I A}-\theta_{\tau, 0}^{C I A}$

Please note that the notation $t$ - $\tau$ must not be interpreted in the way that only the distance between $t$ and $\tau$ matters. Rather, the exact values $t$ and $\tau$ take do matter. Using the definitions of $\theta_{t, 0}^{C I A}$ and $\theta_{\tau, 0}^{C I A}$, we obtain the average bias:

$B_{t-\tau}^{B S A}=B_{t}^{C I A}-B_{\tau}^{C I A}-\theta_{\tau, 0}$.

Equation (8) shows that the condition stated in Equation (6) is neither necessary nor sufficient for a zero average bias. ${ }^{25}$ The necessary and sufficient condition is:

${ }^{24}$ For simplicity, in this section it is assumed that an indefinitely large random sample is available for estimation without sampling error. Furthermore, this and the following arguments use $b(X)=X$ as balancing score. However, with an appropriate change of notation, the results also hold for balancing scores of lower dimension as used in the application. 


$$
\begin{aligned}
B_{t-\tau}^{B S A}=0 \Leftrightarrow \underbrace{\left.E\left(Y_{t}^{n} \mid S=1\right)-E_{X}\left\{g_{t}^{n}\left(x_{t}\right)\right] \mid S=1\right\}}_{B_{t}^{C I A}}=\underbrace{g_{\tau}^{p}-E_{X}\left[g_{\tau}^{n}\left(x_{t}\right) \mid S=1\right]}_{B_{\tau}^{C I A}+\theta_{\tau, 0}} \\
\text { for at least one pair } \tau, t, t \neq \tau, \forall x \in \chi .
\end{aligned}
$$

From an economic point of view this condition is most easily interpreted when $\tau<0$ and $\theta_{\tau, 0}=0$ holds, i.e. there is no effect of a PEP $|\tau|$ periods before a PEP starts. This case implies together with Equation (9) that the bias due to incorrectly assuming CIA $E\left\{\left[Y_{t}^{n}-g_{t}^{n}\left(x_{t}\right)\right] \mid S=1\right\}-$ is the same for both periods $t$ and $\tau$.

The use of BSA as an identifying restriction has several advantages. First, it nests the intuitively appealing CIA assumption when $\theta_{\tau, 0}=0$ holds. In this case, if BSA and CIA are correct, then the test whether the estimated $\theta_{\tau, 0}^{C I A}$ is zero is a joint test for CIA and BSA. If $\theta_{\tau, 0}=0$, that is part of the BSA assumption, does not hold, then it is conceivable that CIA is still valid for $t>0$, but BSA is violated. ${ }^{26}$ It is of practical relevance that for BSA less information is necessary to identify $\theta_{t, 0}$ than for CIA. It is particularly useful that this generalisation is achieved without the need to use instruments, because instruments that for example satisfy the strong assumptions of Angrist, Imbens, and Rubin (1996) are hard to find in general and not available for this particular application. When $X$ contains past values of variables that vary over time it is another practical advantage that $\theta_{t, 0}^{C I A}$ and $\theta_{\tau, 0}^{C I A}$ need not necessarily be estimated using the same sample. Although a panel data set is still useful to keep the two bias-terms $B_{t}^{C I A}$ and $B_{\tau}^{C I A}$ small, the length any individual is required to be observed in the panel data set is not prolonged by the need to compute not only $\theta_{t, 0}^{C I A}$, but also

\footnotetext{
25 It is not necessary to assume constant bias point-wise. One the other hand, (6) would only be sufficient if supplemented by the condition $\theta_{\tau, 0}=0$.

${ }^{26}$ However, in this case CIA must not involve pre-PEP realisations of outcome variables in the conditioning set.
} 
$\theta_{\tau, 0}^{C I A} \cdot{ }^{27}$ This is extensively used in the following empirical part. Compared to conventional difference-in-difference estimators, ${ }^{28}$ BSA has the advantage of being nonparametric so that successful identification does not depend on specific functional forms for the respective expectations. The latter is particularly important for models with qualitative or binary variables as outcomes, because for such models conventional difference-in-difference estimators are very much dependent on the particular functional forms assumed.

However, there are also some problems with the application of this approach. It is not only that the computations for an adequate estimator become more burdensome, but the more serious problem is that there are many 'parameters' to choose. In particular there is the issue of choosing an appropriate $(t, \tau, X)$ combination that makes BSA valid. Unfortunately, there is not much guidance by economic theory or institutional arrangements. But - of course - the same problem exists for the conventional difference-in-difference estimators that are so widely used.

\subsection{Estimation Procedure}

When estimating PEP effects using the nonparametric BSA assumption, it appears to be sensible to use a nonparametric estimation method. Matching methods have recently proved to be useful and flexible estimators for evaluations based on the CIA assumption (see Heckman et al., 1997; Lechner, 1999). Since a 'natural' estimator under the BSA assumption $\hat{\theta}_{t-\tau, N}^{B S A}$ is the difference of two estimates using CIA $\left(\hat{\theta}_{t, N}^{C I A}-\hat{\theta}_{\tau, N}^{C I A}\right)$, we discuss matching estimators in the following. For simplicity we stick to the simple one-to-one matching, i.e. to each PEP observation we match only one non-participant. Such an estimator is inefficient, but

\footnotetext{
${ }^{27}$ If we were to use the same PEP participants, we would require that observations remain in the sample for another $(t-\tau)$ periods (notice that the distance defined by $(t-\tau)$ is not necessarily equal to the corresponding mathematical calculation). As shown in the results section, due to the high attrition rate this would be disastrous for this application.

28 See for example the survey by Meyer (1995).
} 
simplifies computations considerably. In the following we will denote the non-participants matched to the participants as comparisons.

Let us compare $\hat{\theta}_{t-\tau, N}^{B S A}, \hat{\theta}_{t, N}^{C I A}$, and $\hat{\theta}_{\tau, N}^{C I A}$ for two cases. First, assume that $X$ is time-constant, so that both estimators $\hat{\theta}_{t, N}^{C I A}$ and $\hat{\theta}_{\tau, N}^{C I A}$ use the same values of the matching variables $X$. In that case it appears sensible to use a matching protocol ensuring that the same comparison observations are used as matches for both estimations. For ease of exposition assume that observations are ordered such that the $N^{p}$ observations participating in PEPs are followed by the $\left(N-N^{p}\right)$ non-participants. Furthermore denote a comparison observation $j$ matched to PEP participant $i$ as $j(i)$. Then, $\hat{\theta}_{t-\tau, N}^{B S A}\left(=\hat{\theta}_{t, N}^{C I A}-\hat{\theta}_{\tau, N}^{C I A}\right)$ has the following simple form: ${ }^{29}$

$$
\begin{array}{r}
\hat{\theta}_{t-\tau, N}^{B S A}=\frac{1}{N^{p}} \sum_{i=1}^{N^{p}}\left(y_{i, t}^{p}-y_{j(i), t}^{n}\right)-\frac{1}{N^{p}} \sum_{i=1}^{N^{p}}\left(y_{i, \tau}^{p}-y_{j(i), \tau}^{n}\right)=\frac{1}{N^{p}} \sum_{i=1}^{N^{p}}\left[\left(y_{i, t}^{p}-y_{i, \tau}^{p}\right)-\left(y_{j(i), t}^{n}-y_{j(i), \tau}^{n}\right)\right] ; \\
0<i \leq N^{p} ; \quad N^{p}<j \leq N .
\end{array}
$$

However, as discussed above, if it is the aim to reduce the bias in both $\hat{\theta}_{t, N}^{C I A}$ and $\hat{\theta}_{\tau, N}^{C I A}$ used to compute $\hat{\theta}_{t-\tau, N}^{B S A}$ (as seems sensible, but not necessary), the conditioning set should include lagged values of the outcome variables as well. If $Y_{\tau} \in X$, then the case $X_{t}=X_{\tau}$ is no longer sensible because it implies by definition that $\theta_{\tau, 0}^{C I A}=0$ and hence $\theta_{t-\tau, 0}^{B S A}=\theta_{t, 0}^{C I A} \cdot{ }^{30}$

Therefore, it is obvious that there are cases in which the set of conditioning variables depend on the calendar time a PEP takes place. For example, in the empirical part we consider the indication of unemployment after a PEP as an outcome variable, and the indication prior to a PEP as a matching variable (see Section 3 for the importance of unemployment as an

\footnotetext{
${ }^{29}$ We could call this a nonparametric difference-in-difference estimator. More estimators including the case with random attrition and a discussion of variances are contained in Appendix B.2.

${ }^{30} \hat{\theta}_{\tau, N}^{C I A}$ will only be exactly zero, if the sample to draw the comparisons from is sufficiently rich to allow for 'perfect' matches.
} 
eligibility criteria for PEPs). The definition of 'prior to PEP' has to be appropriately changed for the estimation of $\hat{\theta}_{\tau, N}^{C I A}$ by taking the duration of the PEP into account.

Figure 2 clarifies this issue for the case of $\tau=-1$ with an example for one PEP participant. In the evaluation sample we get $\hat{\theta}_{t, N}^{C I A}$. In the bias correction sample we assume an artificial PEP period to get $\hat{\theta}_{\tau=-1, N}^{C I A}$, the effect of the artificial PEP. Because of the BSA $\left(\theta_{\tau, 0}=0\right)$ and that in fact no PEP participation has taken place jet, this is an estimate for the bias. We use it to correct $\hat{\theta}_{t, N}^{C I A}$.

Figure 2: Definition of Periods for the Evaluation Sample and the Bias Correction Sample for One PEP Participant when Time Varying Variables Are Used, $\tau=-1$
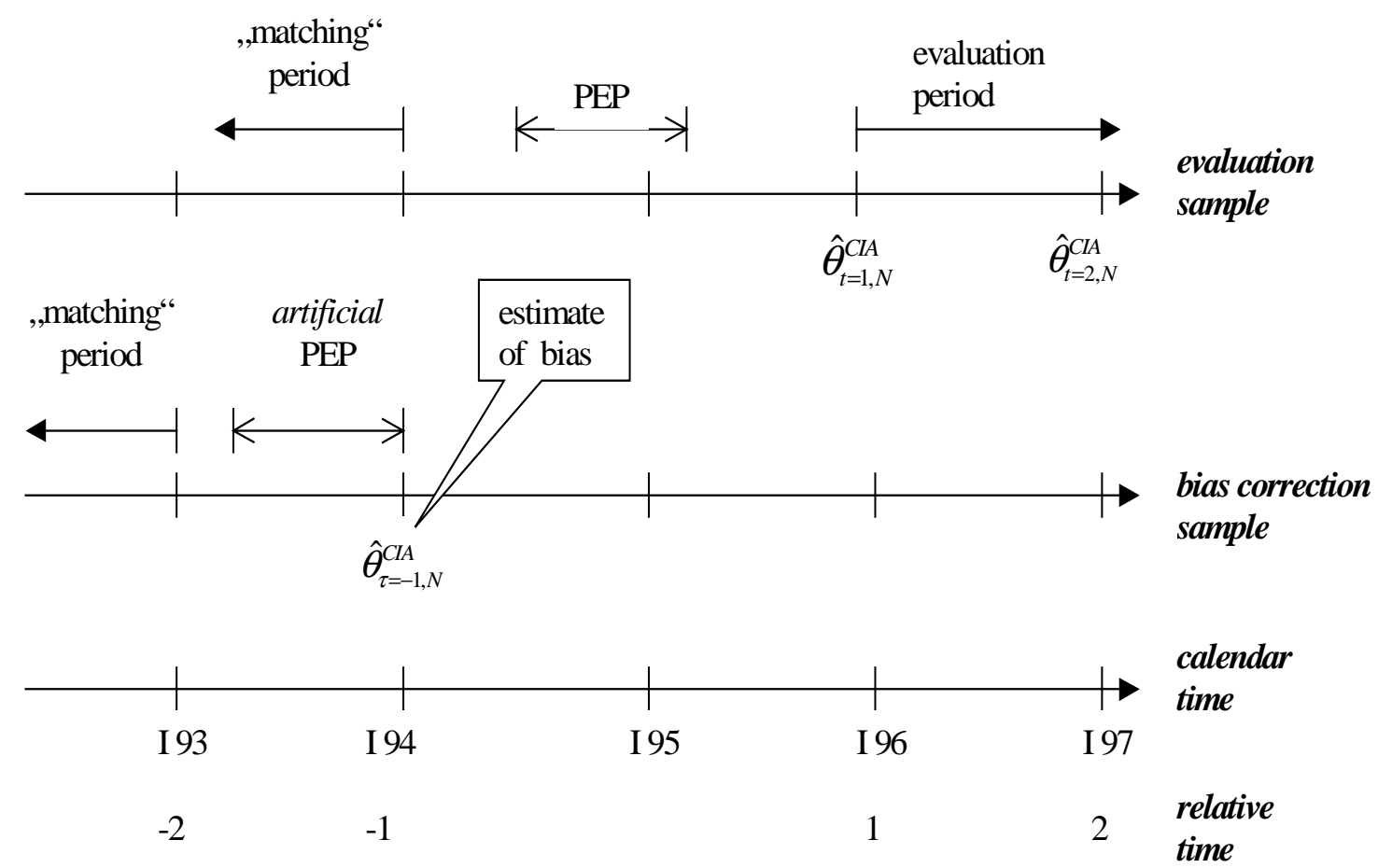

Note: $\quad$ The calendar time shows interviews from I 93 to I 97 . The relative time is defined according to the PEP participation of the person in the example (note that in this example the PEP spell includes one interview which is not necessarily the case). The period artificial PEP has the same duration as the PEP and ends just before the last interview before the PEP $(\tau=-1)$. The evaluation sample is the sample used to compute $\hat{\theta}_{t, N}^{C I A}$ and the bias correction sample is the sample used to compute $\hat{\theta}_{\tau, N}^{C I A} \quad\left(=\hat{B}_{\tau, N}^{C I A}=\hat{B}_{t, N}^{C I A}\right.$ if BSA is valid). 
The assumption of random sampling and large $N$ and $N^{p}$ allows for the usual asymptotic approximation of the variance of matching estimators: ${ }^{31}$

$\operatorname{Var}\left(\hat{\theta}_{t-\tau, N}^{B S A}\right)=\frac{1}{N^{p}}\left[\operatorname{Var}\left(y_{i, t}^{p}-y_{i, \tau}^{p}\right)+\operatorname{Var}\left(y_{j(i), t}^{n}-y_{j^{\prime}(i), \tau}^{n}\right)\right]$

Using standard laws of large numbers and central limit theorems, this estimator is consistent and asymptotically normal. The asymptotic variance can be estimated as follows:

$$
\begin{array}{ll}
\hat{\operatorname{Var}}\left(\hat{\theta}_{t-\tau, N}^{B S A}\right)=\frac{1}{N^{p}}\left[\left(\hat{S}_{t-\tau, N}^{\Delta i}\right)^{2}+\left(\hat{S}_{t-\tau, N}^{\Delta j}\right)^{2}\right] ; & \\
\left(\hat{S}_{t-\tau, N}^{\Delta i}\right)^{2}=\frac{1}{N^{p}} \sum_{i=1}^{N^{p}}\left[\left(y_{i, t}^{p}-y_{i, \tau}^{p}\right)-\left(\bar{y}_{t}^{p}-\bar{y}_{\tau}^{p}\right)\right]^{2} ; & \bar{y}_{t}^{p}-\bar{y}_{\tau}^{p}=\frac{1}{N^{p}} \sum_{i=1}^{N^{p}}\left(y_{i, t}^{p}-y_{i, \tau}^{p}\right) ; \\
\left(\hat{S}_{t-\tau, N}^{\Delta j}\right)^{2}=\frac{1}{N^{p}} \sum_{i=1}^{N^{p}}\left[\left(y_{j(i), t}^{n}-y_{j^{\prime}(i), \tau}^{n}\right)-\left(\bar{y}_{t}^{n}-\bar{y}_{\tau}^{n}\right)\right]^{2} ; & \bar{y}_{t}^{n}-\bar{y}_{\tau}^{n}=\frac{1}{N^{p}} \sum_{i=1}^{N^{p}}\left(y_{j(i), t}^{n}-y_{j^{\prime}(i), \tau}^{n}\right) .
\end{array}
$$

\section{$6 \quad$ Empirical Specification and Results}

\subsection{General Remarks}

In this section the general considerations applied to choose an outcome variable and to set the choice parameters $(t, \tau, X)$ are explained. The details of the estimation are then discussed in the following sections. With respect to the outcome variable the labour market states unemployment and employment at specific periods after a PEP $(t)$ are considered, because they constitute the official targets of the programme. It would also be very interesting to see how large the earnings gains - if any - are from PEP participation, but we did not succeed in

\footnotetext{
${ }^{31}$ Note that the following formulas have been obtained using the approximation that the fact that the pairs have been selected by an estimated score can be ignored.
} 
constructing an earnings variable based on a definition that is consistent for all yearly interviews.

First, we assume that the true effect of a PEP before the PEP started is indeed zero, $\theta_{\tau, 0}=0$ for $\tau<0$. The specific institutional regulations discussed in Section 3 make it difficult for an individual to anticipate a PEP participation and change the behaviour because of a potential PEP participation. Especially, in combination with the high unemployment rate in East Germany it is unlikely that someone is willing to give up a job to increase the chance to get into a PEP.

Choosing appropriate values for $t$ and $\tau$ is largely driven by sample size considerations. As can be seen in Table 10 and in Appendix D, choosing $t$ larger than 2 will typically lead to a very small sample, in particular when time varying variables are included in $X$. This is due to the total length (max. 6 years) and the high attrition rates of the panel.

The choice of $\tau$ is also influenced by considerations of Ashenfelters dip. It is observed that on average before participating in any kind of active labour market programme individuals experience a drop in income. This holds for employment was well. It is not at all clear if this drop is transitory or permanent, but the choice of $\tau$ depends on this knowledge. In a recent work Heckman and Smith (1999) find for the US that the drop in income is not permanent. Furthermore, they find that apart from eligibility participation in programmes depends heavily on changes in labour market status prior to the programme. Using different non-experimental estimators - including a difference-in-difference approach similar to the one used here - they show that the resulting bias can be reduced substantially by conditioning on variables influencing the individual programme participation.

In East Germany and with respect to employment status a permanent dip is more probable due to the economic conditions, especially rising long term unemployment. Individual decisions play no role in participation process, and therefore an individual shock in labour market status 
might be less relevant. Nevertheless, in the matching process we take apart from other variables explicitly care of the labour market status prior to PEP (employment and unemployment). Furthermore, in this problematic labour market any 'temporary' shock leading to unemployment will be made permanent very soon, due to the lack of job offers. When there is no transitory dip, it is intuitively most plausible to choose the relevant points in time ( $\mathrm{t}$ and $\tau$ ) as close together as possible because the social and economic environment is most similar. A possible permanent dip would call for a $\tau$ near to the start of PEP as well. Therefore, and because of sample size considerations, in most cases presented here $\tau$ is set to the last interview before a $\operatorname{PEP}(\tau=-1)$.

When choosing the variables to be included in $X$, our main strategy is to minimise the bias in $\hat{\theta}_{\tau, N}^{C I A}$ and $\hat{\theta}_{t, N}^{C I A}$. Although intuitively appealing, this need not necessarily be the best strategy because all that is needed is that $\hat{\theta}_{\tau, N}^{C I A}$ and $\hat{\theta}_{t, N}^{C I A}$ are equally biased. Therefore, and also because there is a trade-off between sample size and the number of components in $X$ (in particular for time varying variables), we present results for more or less rich specifications of $X$. Apart from the propensity score and an indicator for an interview in particular waves the richest version includes information on the labour market status (unemployed and employed), variables containing job position, firm size, and dummies for some industrial sectors (agricultural, chemical, public) for the current or last employer, the highest vocational degree, and the unemployment rate in the region. Unemployment, and especially long term unemployment, is an important reason for PEP participation, and we use the labour market status as one indicator for this. The employer variables are included because of their relationship with the probability to participate in a PEP, especially in a large employerfounded PEP (see Section 3). The agricultural, chemical, and public sectors were hit harder than the average by the economic changes and laid off more employees. Furthermore there was a large number of PEPs in these sectors which again justifies their inclusion in the 
matching. The level of the regional unemployment rate is included because the amount of money the labour offices can spend on PEP partly depends on it. Due to sample size considerations variables measuring the employment history contain only up to two periods.

Since our richer specifications include also time varying variables as components of $X$, and because PEPs start at different dates for different individuals, there is the issue of choosing an appropriate balancing score that allows us to address these issues. Here we rely on a split balancing score, $\left(V \beta_{0}, M\right)$, a combination of an index of the participation probability based on time constant variables $\left(V \beta_{0}, V\right.$ denotes the time constant variables in $X, \beta_{0}$ is a fixed parameter vector) and time varying variables $(M$, which denotes the time variant variables in $X)$. As start date necessary to compute the relevant value for $M$ for the non-participants the PEP start date of the particular treated observation a match is search for is used. The estimation of $V \beta_{0}$ is discussed below. Some details on the matching process are presented in Appendix B.1. Lechner (1999) discusses the use of different starting dates for the computation of $\hat{\theta}_{t, N}^{C I A}$ extensively including the approach used here. For more details, especially on the additionally necessary assumptions and issues of computation, the reader is referred to the this paper.

\subsection{Propensity Score}

We specify the propensity score as a probit model and test the specification extensively using specification tests against heteroscedasticity, omitted variables, nonnormality (score tests) and general misspecification (information matrix test). The probit specification includes variables capturing gender, age, schooling, university degree and degree from technical schools as well as the regional unemployment and PEP rates and disaggregated local information. ${ }^{32}$ Furthermore we include variables indicating panel participation and interactions of the panel

\footnotetext{
${ }^{32}$ See Table 14 in Appendix A for more information on the definition of the variables.
} 
participation with gender. The results of the estimation as well as of the tests are presented in Tables 6 and 7.

Table 6: Propensity Score: Estimated Coefficients and Results for Score Test Against Heteroscedasticity

\begin{tabular}{|c|c|c|c|c|c|c|}
\hline \multirow{2}{*}{ Variable } & \multicolumn{4}{|c|}{ Estimation } & \multicolumn{2}{|c|}{ Heteroscedasticity test } \\
\hline & Coef. & Std.err & P-value & $\begin{array}{c}\text { Average } \\
\left.\text { derivatives }^{a}\right)\end{array}$ & $\chi^{2}(1)$ & P-value \\
\hline \multirow{2}{*}{$\begin{array}{l}\text { Const. } \\
\text { Gender: Female }\end{array}$} & -2.47 & .53 & .000 & --- & --- & --- \\
\hline & 0.09 & .09 & .30 & .013 & 7.5 & .006 \\
\hline Between 25 and 35 & 0.33 & .07 & $.000^{\circ}$ & .057 & 0.0 & .99 \\
\hline Between 35 and 45 & 0.37 & .07 & .000 & .050 & 0.3 & .56 \\
\hline Between 45 and 55 & 0.27 & .08 & .001 & .042 & 1.5 & .22 \\
\hline $\begin{array}{l}\text { Schooling: University entrance degree } \\
\text { (12 years) }\end{array}$ & -0.18 & .07 & .007 & -.025 & 1.4 & .25 \\
\hline Medium (10 years) & -0.19 & .05 & .000 & -.027 & 0.1 & .78 \\
\hline Technical school (Fachschule) & -0.10 & .04 & .019 & -.014 & 0.6 & .45 \\
\hline University & -0.12 & .06 & .055 & -.016 & 1.9 & .17 \\
\hline \multicolumn{7}{|l|}{ Answered questionnaires only in } \\
\hline Mar. '92, Sep. '92 & -0.36 & .08 & .000 & -.050 & 0.6 & .46 \\
\hline Sep. '93 & -0.36 & .09 & .000 & -.045 & 0.0 & .99 \\
\hline Sep. '93, Sep. '94 & -0.46 & .10 & .000 & -.052 & 2.2 & .14 \\
\hline Sep.' 93, Sep. '94, Sep. '95 & -0.23 & .15 & .12 & -.029 & 0.4 & .53 \\
\hline Sep. ' 95 , Sep. ' 96 & -0.11 & .18 & .53 & -.015 & 0.0 & .98 \\
\hline Sep. ' 95 , Sep. ' 96 , Sep. ' 97 & 0.08 & .15 & .58 & .012 & 0.0 & .86 \\
\hline Sep.' 96 & -0.04 & .10 & .69 & -.006 & 1.9 & .16 \\
\hline Sep. ' 96 , Sep. ' 97 & -0.15 & .10 & .15 & -.020 & 0.0 & .87 \\
\hline \multicolumn{7}{|l|}{ Female and answered questionnaires in } \\
\hline Mar. ' 92, Sep. ' 92 & -0.17 & .11 & .097 & -.023 & 7.9 & .005 \\
\hline Sep. ' 93 & -0.30 & .12 & .014 & -.037 & 3.8 & .052 \\
\hline Sep. '93, Sep. '94 & -0.14 & .14 & .34 & -.018 & 0.5 & .46 \\
\hline Sep.' 93, Sep. ' 94, Sep. '95 & -0.11 & .20 & .60 & -.014 & 0.6 & .43 \\
\hline Sep. '95, Sep. '96 & -0.12 & .26 & .64 & -.016 & 0.5 & .46 \\
\hline Sep. '95, Sep. '96, Sep. '97 & 0.02 & .20 & .91 & .003 & 0.1 & .73 \\
\hline Sep.' 96 & 0.16 & .13 & .23 & .025 & 1.2 & .27 \\
\hline Sep. '96, Sep. '97 & 0.29 & .14 & .033 & .049 & 0.0 & .88 \\
\hline Cities and areas & & & & & & \\
\hline City of Dessau & -0.32 & .10 & .002 & -.038 & 0.39 & .53 \\
\hline City of & -0.38 & .08 & .000 & -.044 & 0.0 & .96 \\
\hline Magdeburg & -0.18 & .06 & .002 & -.023 & 1.2 & .27 \\
\hline Ascherleben-Staßfurt & 0.10 & .08 & .23 & .015 & 0.2 & .70 \\
\hline Anhalt-Zerbst & 0.07 & .10 & .47 & .011 & 3.8 & .052 \\
\hline Bitterfeld & 0.35 & .09 & .000 & .061 & 0.0 & .91 \\
\hline Quedlinburg & 0.33 & .09 & .000 & .058 & 0.7 & .42 \\
\hline Wernigerode & -0.29 & .10 & .004 & -.035 & 1.2 & .28 \\
\hline Area of Bördekreis & & & & & & \\
\hline And region of Halberstadt & -0.27 & .20 & .17 & -.033 & 0.0 & .87 \\
\hline And region of Magdeburg & 0.23 & .11 & .035 & .038 & 0.4 & .54 \\
\hline
\end{tabular}
To be continued. 


\begin{tabular}{|c|c|c|c|c|c|c|}
\hline & \multicolumn{4}{|c|}{ Estimation } & \multicolumn{2}{|c|}{ Heteroscedasticity test } \\
\hline Variable & Coef. & Std.err & P-value & $\begin{array}{c}\text { Average } \\
\text { derivativesa) }\end{array}$ & $\chi^{2}(1)$ & P-value \\
\hline $\begin{array}{l}\text { Unemployment rate in region (mean) } \\
\text { PEP rate in region (mean) }\end{array}$ & $\begin{array}{r}6.25 \\
-3.04\end{array}$ & $\begin{array}{l}3.15 \\
6.92\end{array}$ & $\begin{array}{l}.047 \\
66\end{array}$ & $\begin{array}{r}.005 \\
-.001\end{array}$ & $\begin{array}{l}0.6 \\
29\end{array}$ & $\begin{array}{l}.45 \\
087\end{array}$ \\
\hline
\end{tabular}

Note: Coefficients that are significant at the $5 \%$ level are in bold letters. Standard errors and tests are computed using the expected hessian as part of the White (1982) approach; lagrange multiplier (LM) test is on heteroscedasticity due to single variables (Davidson and MacKinnon, 1984).

Dependent variable: dummy variable for participation in PEP. Reference group: male, age between 22 and 25 , schooling: none or lowest degree, living in any other area, answered questionnaire only in Sep. '93, '94, '95 and '96 or only in Sep. '93, '94, '95, '96 and ' 97 or only in Sep. '94, '95, '96 and '97 or only in Sep. '94, '95 and '96.

Total number of observations: 13,688 observations (1,123 PEP participants).

a) Change of participation probability for the change from 0 to 1 in the case of dummies, changes of $+/-0.14 \%$ and $+-0.02 \%$ for the continuos variables unemployment rate in region and PEP rate in region, respectively (equal to one standard deviation).

Table 7: Other Specification Tests for the Participation Probit (Partial)

\begin{tabular}{|c|c|c|c|c|}
\hline & & $\chi^{2}(d f)$ & Df & P-value \\
\hline $\begin{array}{l}\text { Score } \\
\text { Inform }\end{array}$ & $\begin{array}{l}\text { st against nonnormality } \\
\text { tion matrix test: }\end{array}$ & 1.2 & 2 & .55 \\
\hline & All indicators & 510 & 447 & .020 \\
\hline & Only main diagonal indicators & 43 & 36 & .20 \\
\hline Note: & $\begin{array}{l}\text { Sore test suggested by Bera, Jarque, and } \mathrm{L} \\
\text { The IM tests are computed using the sec } \\
\text { properties. IM checks the validity of the } \\
\text { estimated by maximum likelihood. Only ma } \\
\text { the main diagonal of the difference between } \\
\text { See also note on Table } 6 \text {. }\end{array}$ & $\begin{array}{l}\text { 84) tests n } \\
\text { arsion suge } \\
\text { ation matri } \\
\text { gonal indic } \\
\text { (outer prod }\end{array}$ & $\begin{array}{l}\text { gainst } \\
\text { y Orm } \\
\text { ty that } \\
\text { ers to } \\
\text { adient) }\end{array}$ & $\begin{array}{l}\text { son family } \\
\text { that has } \\
\text { a correct } \\
\text { cusing as } \\
\text { ected hessi }\end{array}$ \\
\hline
\end{tabular}

The estimation results show a lower conditional participation probability for the very young age group (22 to 25 in 1993, chosen as the reference group) compared to all other age groups and a low school degree (chosen as the reference group) is related to a higher probability to participate in PEP. Furthermore, a degree from a technical school or an university is related to a lower probability, although the coefficient of university is only significant at the $6 \%$-level. Regional heterogeneity is important and significant as well. The positive sign of the unemployment rate corresponds to our expectations, while the PEP rate is insignificant. Furthermore, some dummies for cities and areas show more diversity in the PEP participation than is explained by the regional unemployment rate (note that cities and areas are subdivisions of the regions). Cities with their different and much more diversified economic 
structure and in general lower unemployment rates relate to lower participation probabilities. The positive signs pick out regions with either a high concentration of a specific industry or with a single but very large PEP. The concentration of PEPs and - especially of large PEPs differed across industries and the local concentration of specific industrial sectors was high in the GDR, which explains at least part of the findings. An example is the area of Bitterfeld with a high concentration of the chemical industry as well as an above-average PEP concentration. The results when estimating the propensity score separately for females and males do not differ substantially. ${ }^{33}$

\subsection{Evaluation Results}

Let us start the discussion of the evaluation results for several specifications of $X$ by considering the least demanding case first. This is the case when only the propensity score and indicators for a valid interview in a particular wave are used for matching. The results in Table 8 show how the number of valid observations depends on the length of time the individual is required to remain in the sample before or after a PEP. The results prior to PEPs clearly indicate that this specification leads to a biased estimate $\hat{\theta}_{t, N}^{C I A}$.

Table 8: $\hat{\theta}_{N}^{\mathrm{CIA}}$ Computed with Time-Constant Match Variables Only

\begin{tabular}{|c|c|c|c|c|c|c|c|}
\hline Period & $\hat{\theta}_{t, N}^{\mathrm{CIA}}$ & $\mathrm{P}$-value & Obs. & Period & $\hat{\theta}_{\tau, N}^{\mathrm{CIA}}$ & $\mathrm{P}$-value & Obs. \\
\hline 1 & 29 & .000 & 743 & -1 & 29 & .000 & 228 \\
\hline 2 & 17 & .000 & 459 & -2 & 25 & .000 & 71 \\
\hline 3 & 15 & .000 & 192 & -3 & 17 & .11 & 29 \\
\hline 4 & 10 & .095 & 67 & -4 & 15 & .36 & 13 \\
\hline
\end{tabular}

The following tables provide information on the average expected unemployment probability in the sample of PEP participants (employment and out of labour force probabilities in Table

\footnotetext{
33 Separate estimates of the propensity score were used for the gender-specific results presented in the following section. The results are available on request from the authors and are also included in Eichler and Lechner
} 
12), separated for the case of participation in a PEP $\left(\hat{E} Y_{t}^{p} \mid S=1\right)$ and the case of not participating in a PEP $\left(\hat{E} Y_{t}^{n} \mid S=1\right) .{ }^{34}$ The resulting estimate of the causal effect $\hat{\theta}_{t-\tau, N}^{\mathrm{BSA}}$ given the BSA is presented as well.

When correcting the bias, there are two ways to proceed. First one could only use those observations observed at least one period before and after a PEP. This reduces the sample size after a PEP considerable as can be seen from the results in Table 9. The alternative of using all observations that are available at each time period is presented in Table 9 as well. In both cases we consider also different choices for $\tau$ : Either it is chosen symmetrically to $t(\tau=-\mathrm{t})$ or it is fixed at $-1(\tau=-1)$. For the reason explained above the latter is the preferred version.

Table 9: $\hat{\theta}_{t-\tau, N}^{\mathrm{BSA}}$ Computed with Time-Constant Match Variables Only

\begin{tabular}{|c|c|c|c|c|c|c|}
\hline Period & $\hat{E}\left(Y_{t}^{p} \mid S=1\right)$ & $\hat{E}\left(Y_{t}^{n} \mid S=1\right)$ & $\hat{\theta}_{t-\tau, N}^{\mathrm{BSA}}$ & P-value & Obs. $t$ & Obs. $\tau$ \\
\hline & \multicolumn{6}{|c|}{ Balanced designa), $\tau=-\mathrm{t}$} \\
\hline 1 & 36 & 38 & -2 & .64 & 228 & 228 \\
\hline 2 & 37 & 26 & 11 & .44 & 27 & 27 \\
\hline \multirow[t]{2}{*}{3} & --- & --- & --- & --- & 0 & 0 \\
\hline & \multicolumn{6}{|c|}{ Balanced designa), $\tau=-1$} \\
\hline 1 & 36 & 38 & -2 & .64 & 228 & 228 \\
\hline 2 & 25 & 32 & -7 & .30 & 85 & 85 \\
\hline \multirow[t]{2}{*}{3} & 31 & 52 & -20 & .11 & 25 & 25 \\
\hline & \multicolumn{6}{|c|}{ Unbalanced design, $\tau=-t$} \\
\hline 1 & 41 & 40 & 1 & .84 & 743 & 228 \\
\hline 2 & 30 & 38 & -8 & .25 & 459 & 71 \\
\hline \multirow[t]{2}{*}{3} & 23 & 26 & -3 & .82 & 192 & 29 \\
\hline & \multicolumn{6}{|c|}{ Unbalanced design, $\tau=-1$} \\
\hline 1 & 41 & 40 & 1 & .84 & 743 & 228 \\
\hline 2 & 30 & 41 & -12 & .010 & 459 & 228 \\
\hline 3 & 23 & 37 & -14 & .007 & 192 & 228 \\
\hline
\end{tabular}

a) The same observations are used to compute $\hat{\theta}_{t, N}^{\mathrm{CIA}}$ and $\hat{\theta}_{\tau, N}^{\mathrm{CIA}}$.

For the case of a symmetric choice of $t$ and $\tau$, no significant effects appear. However for $t$ larger than 1 and $\tau$ fixed at -1 significant positive effects of PEPs appear at least for the unbalanced design. With respect to problems that might be due to possibly nonignorable panel 
attrition, we note that the results based on the balanced and unbalanced designs are not contradictory.

In order to reduce the bias of both $\hat{\theta}_{t, N}^{\mathrm{CIA}}$ and $\hat{\theta}_{\tau, N}^{\mathrm{CIA}}$, labour market states prior to a PEP are included in $X$ as well. From the discussion in Section 3 it is clear that at least previous unemployment is an important component of the participation decision. In addition to unemployment we include now all variables discussed in Section 6.1. Based on the considerations in Section 6.1 and the potential loss of observations we consider only the case of $\tau=-1$ and a unbalanced design.

From the second part of Table 10 we see that the bias when assuming CIA appears indeed to be slightly reduced. Furthermore, the match with respect to unemployment in the estimation sample as well as in the bias correction sample is good, as the values for $\tau=-1$ and $\tau=-2$, respectively, indicate (matching in the bias correction sample is done at the last interview prior to the artificial PEP, which in a lot of cases is -2 ). A more complete analysis of the quality of the matches can be found in Appendix C. The value for $\tau=-1$ in the bias correction sample indicates that there is still a substantial bias in the CIA results (given the bias stability assumption is correct). Figure 3 visualises the results given in Table 10 .

Table 10: $\hat{\theta}_{N}^{\mathrm{CIA}}$ Computed with Time-Varying Matching Variables

\begin{tabular}{|c|c|c|c|c|c|c|c|c|c|c|}
\hline \multirow[b]{2}{*}{ Period } & \multicolumn{3}{|c|}{ Evaluation sample } & \multicolumn{3}{|c|}{ Bias correction sample } & \multirow[b]{2}{*}{ Period } & \multicolumn{3}{|c|}{ Evaluation sample } \\
\hline & $\hat{\theta}_{\tau, N}^{\mathrm{CIA}}$ & $\mathrm{P}$-value & Obs. & $\hat{\theta}_{\tau, N}^{\mathrm{CIA}}$ & P-value & Obs. & & $\hat{\theta}_{t, N}^{\mathrm{CIA}}$ & $P$-value & Obs. \\
\hline-1 & 0 & 1.00 & 231 & 28 & .000 & 144 & 1 & 11 & .008 & 231 \\
\hline-2 & 7 & .37 & 71 & 1 & .78 & 143 & 2 & 0 & 1.00 & 88 \\
\hline-3 & 7 & .56 & 29 & 14 & .10 & 52 & 3 & 11 & .34 & 27 \\
\hline Note: & $\begin{array}{l}X \text { used fo } \\
\text { employme } \\
\text { public), pr } \\
\text { before } \mathrm{PE} \\
\text { The evalu } \\
\text { to estimat } \\
\text { See also }\end{array}$ & $\begin{array}{l}\text { natching: } \\
\text { pre-PEP } \\
\text { PEP vocat } \\
\text { used). } \\
\text { on sample } \\
\text { he bias. }\end{array}$ & $\begin{array}{l}\text { tial pro } \\
\text { nemplc } \\
\text { nal dec } \\
\text { used }\end{array}$ & $\begin{array}{l}\text { ity, dur } \\
\text { nt, pre- } \\
\text { pre-PE } \\
\text { npute th }\end{array}$ & $\begin{array}{l}\text { ies indicat } \\
\begin{array}{l}\text { P job pos } \\
\text { irm size, } p\end{array} \\
\text { effect of } P E\end{array}$ & $\begin{array}{l}\text { valid } \\
\text { on, pre } \\
\text { PEP u } \\
\text { if CIA }\end{array}$ & $\begin{array}{l}\text { rviews in } \\
\text { P indust } \\
\text { nploymen } \\
\text { valid, the }\end{array}$ & $\begin{array}{l}\text { irticular } \\
\text { sector } \\
\text { te in } r\end{array}$ & $\begin{array}{l}\text { ave, pre-P } \\
\text { agricultura } \\
\text { ion (only la } \\
\text { tion sample }\end{array}$ & $\begin{array}{l}\text { full time } \\
\text { chemical } \\
\text { intervien } \\
\text { the usec }\end{array}$ \\
\hline
\end{tabular}

${ }^{34}$ The first of these values is the actual average in the sample while the second is estimated. 
Figure 3: $\hat{\theta}_{N}^{\mathrm{CIA}}$ Computed with Time-Varying Matching Variables

\section{Evaluation Sample}

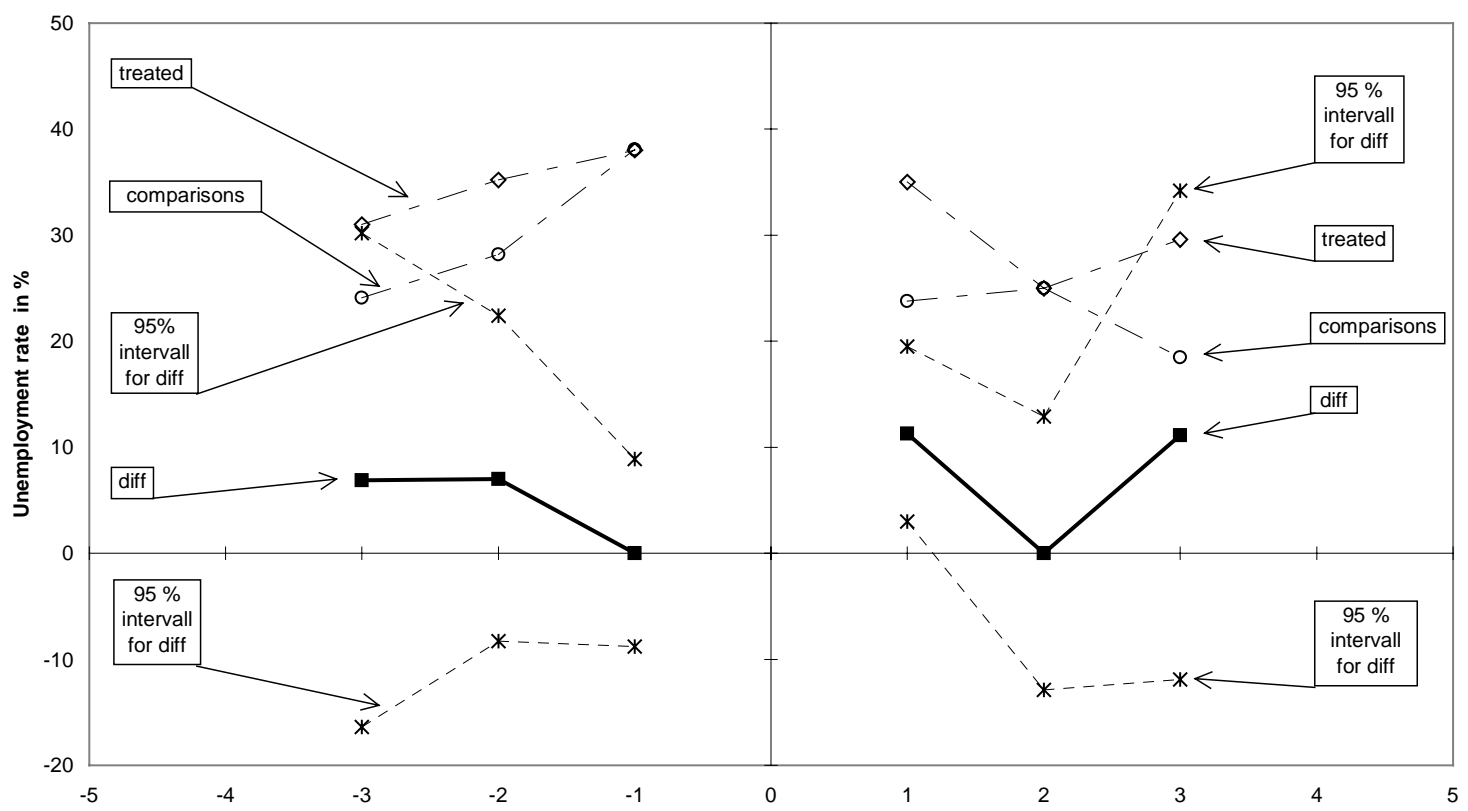

Bias Correction Sample

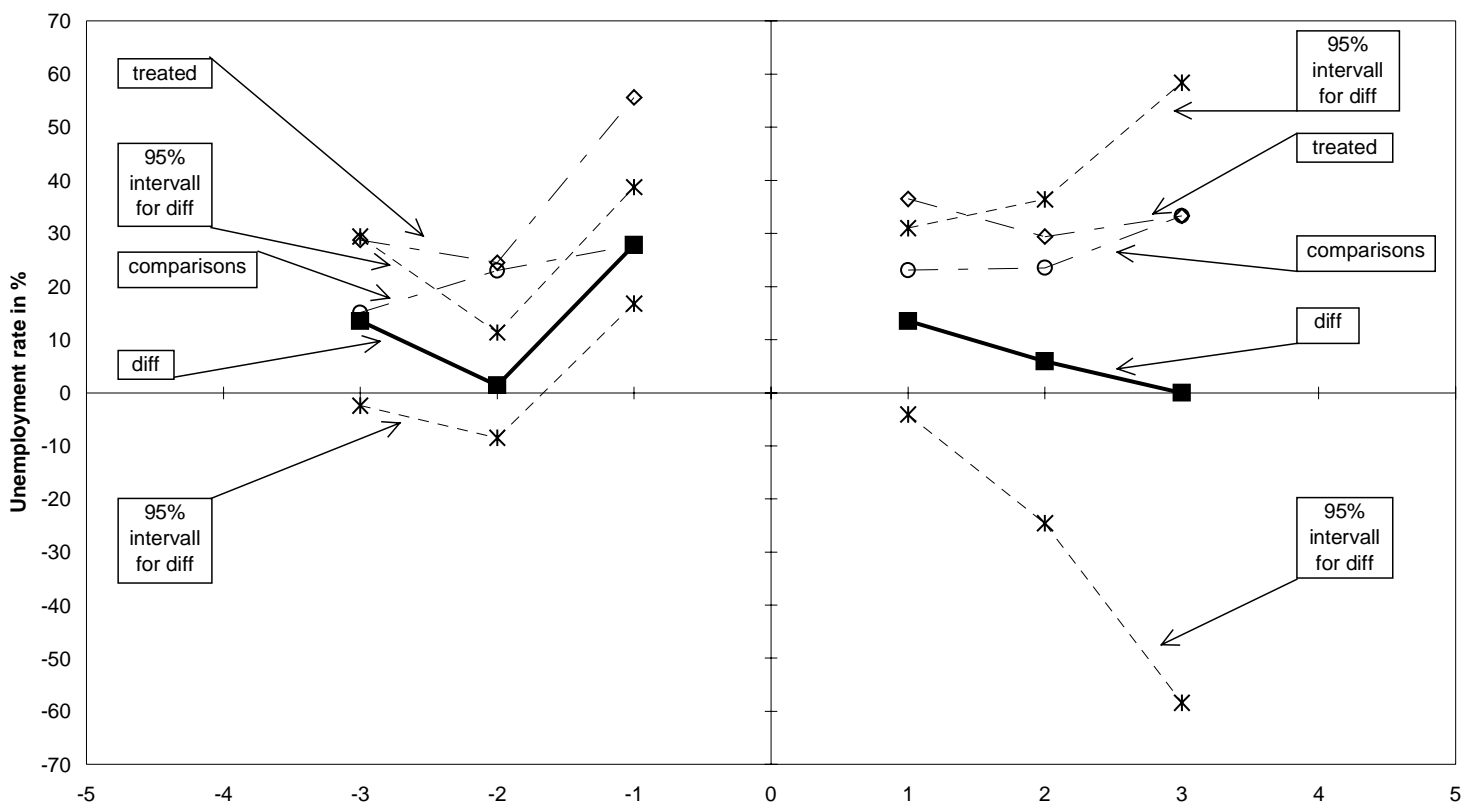

Note: $\quad$ X-axis: Relative time; Y-axis: Unemployment rate in \%

Treated is the estimated unemployment rate for participants, comparisons the estimated unemployment rate for participants had they not participated (the unemployment rate of the matched comparison sample), and diff the difference between these two, $\hat{\theta}_{N}^{\text {CIA }}$.

See also note on Table 10.

Table 11 shows the basic result of our paper. The value of -17 for $t=1$ indicates that there appears to be a substantial individual gain (ie. a reduction in unemployment probabilities) 
from participating in PEP. The average probability of unemployment for an individual in the sample of PEP participants - equivalent to the unemployment rate in the sample - is reduced from $52 \%$ to $35 \%$ at the time of the first interview after PEP ended. The results for higher values of $t$ indicate that this is not only a short term effect, although the numbers should be considered with care. At least for $t=3$ the number of observations is too small to draw conclusions. Note that the bias correction not only changes but reverses the conclusions that would be drawn if CIA was believed to be valid, even when the richest specification of matching possible with the available data is used.

Table 11: $\hat{\theta}_{t-\tau, N}^{\mathrm{BSA}}$ Computed with Time-Varying Matching Variables

\begin{tabular}{|c|c|c|c|c|c|c|}
\hline \multirow[b]{2}{*}{ Period } & \multicolumn{6}{|c|}{ Unbalanced design, $\tau=-1$} \\
\hline & $\hat{E}\left(Y_{t}^{p} \mid S=1\right)$ & $\hat{E}\left(Y_{t}^{n} \mid S=1\right)$ & $\hat{\theta}_{t-\tau, N}^{\mathrm{BSA}}$ & P-value & Obs. $t$ & Obs. $\tau$ \\
\hline 1 & 35 & 52 & -17 & .015 & 231 & 144 \\
\hline 2 & 25 & 53 & -28 & .001 & 88 & 144 \\
\hline \multirow[t]{2}{*}{3} & 30 & 46 & -17 & .21 & 27 & 144 \\
\hline & \multicolumn{6}{|c|}{ Unbalanced design, $\tau=-1$; women only } \\
\hline 1 & 42 & 58 & -16 & .086 & 108 & 90 \\
\hline 2 & 38 & 61 & -24 & .066 & 40 & 90 \\
\hline 3 & 36 & 79 & -43 & .032 & 14 & 90 \\
\hline \multicolumn{7}{|c|}{ Unbalanced design, $\tau=-1$; men only } \\
\hline 1 & 29 & 46 & -17 & .064 & 123 & 54 \\
\hline 2 & 14 & 44 & -29 & .003 & 48 & 54 \\
\hline 3 & 23 & 43 & -20 & .21 & 13 & 54 \\
\hline
\end{tabular}

The lower part of Table 11 shows gender-specific results. Some of the tests we performed on the probit suggested such a split to be necessary (see Appendix C). Furthermore, as described in Section 2.3, the composition of PEP participants with respect to gender changed dramatically over time. Although the estimates are less precise because of the reduced sample sizes, the differences for the two samples are not very large and they confirm the previously obtained results. Note that the effects of PEP are similar even when the levels of unemployment differ substantially for the two samples. 
Table 12 provides information on the effects of PEP participation on regular employment and out of labour force respectively. The reduced unemployment probability at the first interview after PEP is due to a higher employment probability. For men this result holds more or less for longer periods after PEP as well, but for women from $t=2$ on a large share of the reduced unemployment probability is due to a higher out of labour force probability. This is consistent with the hypothesis that women drop out of the labour force when their unemployment benefit period ends. $^{35}$

Table 12: $\hat{\theta}_{t-\tau, N}^{\mathrm{BSA}}$ for Employment and Out of Labour Force Computed with Time-Varying

Matching Variables

\begin{tabular}{|c|c|c|c|c|c|c|c|c|}
\hline \multirow[t]{2}{*}{ Period } & $\hat{E}\left(Y_{t}^{p} \mid S=1\right)$ & $\hat{E}\left(Y_{t}^{n} \mid S=1\right)$ & $\hat{\theta}_{t-\tau, N}^{\mathrm{BSA}}$ & $P$-value & $\hat{E}\left(Y_{t}^{p} \mid S=1\right)$ & $\hat{E}\left(Y_{t}^{n} \mid S=1\right)$ & $\hat{\theta}_{t-\tau, N}^{\mathrm{BSA}}$ & P-value \\
\hline & \multicolumn{4}{|c|}{$\begin{array}{c}\text { Employment } \\
\text { Women and men }\end{array}$} & \multicolumn{4}{|c|}{$\begin{array}{l}\text { Non employment } \\
\text { Women and men }\end{array}$} \\
\hline 1 & 55 & 40 & 14 & .043 & 10 & 8 & 2 & .58 \\
\hline 2 & 56 & 42 & 14 & .13 & 19 & 5 & 14 & .021 \\
\hline \multirow[t]{2}{*}{3} & 52 & 57 & -5 & .74 & 19 & -3 a) & -- & --- \\
\hline & \multicolumn{4}{|c|}{ Women only } & \multicolumn{4}{|c|}{ Women only } \\
\hline 1 & 42 & 25 & 17 & .074 & 17 & 18 & -1 & .89 \\
\hline 2 & 33 & 24 & 9 & .48 & 30 & 15 & 15 & .16 \\
\hline \multirow[t]{2}{*}{3} & 43 & 14 & 29 & .17 & 21 & 7 & 14 & .34 \\
\hline & \multicolumn{4}{|c|}{ Men only } & \multicolumn{4}{|c|}{ Men only } \\
\hline 1 & 66 & 51 & 14 & .12 & 5 & 3 & 2 & .66 \\
\hline 2 & 75 & 54 & 21 & .059 & 10 & 3 & 8 & .25 \\
\hline 3 & 62 & 53 & 8 & .62 & 15 & 4 & 11 & .41 \\
\hline Note: & & & nt and & of labour & ce. See note & Table 10; numb & r of obs & vations ca \\
\hline
\end{tabular}

We also studied the (intermediate) case of using only unemployment and employment as time varying match variables. Other specifications used information on employment histories for two periods. Many specifications with different combinations of these and the above discussed variations (balanced and unbalanced design, choice of $t$ and $\tau, X$ variables used in matching, different outcome variables, separate estimations for men and women) have been checked. Some of the results are contained in Appendix D, more can be found in Eichler and

\footnotetext{
35 PEP participation creates a new claim for unemployment benefits.
} 
Lechner (1998). ${ }^{36}$ NonE of the results from these specifications differ substantially from the results presented in this section.

With the limited information available in the data we could not find an indication of contamination bias with regard to different kinds of training. Nevertheless, contamination might be a potential problem. Using a preliminary release of the data for 1997 and 1998 with consistent PEP and training information since 1990 and applying our exclusion rules, we found 689 persons who participated in PEP, roughly $10 \%$ of the sample. Of these, 321 had some kind of training as well, 115 after the end of their PEP spell. On average persons with training before the PEP participation are older, and more females are in this group. This is not observed for the people with training after PEP, but this people have on average less formal education (school and occupational training). It should be noticed that the numbers above overstate the problem in this study because it uses a balanced structure from 1990 to $1997 / 1998$, which is not the case in the data used. Apart from the descriptive information above we used subpopulations of the actually used data with consistent training definitions to check for any indication of contamination bias. But definitions of and information on training in the data changes very much between waves and the subpopulations got rather small.

\section{Conclusion}

Using nonparametric difference-in-difference methods this paper analyses the effects of public employment programmes (PEPs) in East Germany. Because there does not appear to be any suitable data accessible to the scientific community for all of East Germany, we restrict our analysis to the East German state of Sachsen-Anhalt. The available data make the use of difference-in-difference methods almost imperative to identify the effects of PEPs.

\footnotetext{
${ }^{36}$ The paper is downloadable from the Internet at: http:// www.siaw.unisg.ch/lechner/publica/98e01.html.
} 
Our main findings suggest that individuals participating in a PEP benefit indeed considerably from participation, since their unemployment risk is reduced by a substantial amount. Furthermore, there is some indication that this is not only a short term effect, although inference gets difficult because of decreasing numbers of observations for longer periods after PEP. For men the majority of the reduced unemployment risk is due to an increased employment probability. For women that is only true for the first period after PEP, while for later periods the effect of non-participation in the labour market dominates. These general findings are not contradicted when using several different specifications.

However, one should be careful in interpreting these results: Individual gains for the participants do not necessarily translate into benefits for the economy as a whole, because the costs of PEPs and market interactions are ignored. The latter occur through possible negative impacts for competing private firms as well as through a possibly changing labour market supply structure during and after PEPs. No estimates of this effects of PEPs exist for East Germany, but Steiner, Wolf, Egeln, Almus, Schrumpf, and Feldotto (1998) find some hints that earlier found positive effects of public training programs in East Germany do not correspond to similar effects on the macroeconomic level. ${ }^{37}$ Following from the above discussion, a cost-benefit analysis based on the results of this study and the expenditures on PEPs would not be valid. Furthermore, such an analysis has to take account of other goals and effects of PEP, which we have no information on. ${ }^{38}$

Apart from combining the results of this study with information on costs, other benefits of PEPs, and market interactions to achieve a cost-benefit-analysis, future research should concentrate the robustness of the results. Furthermore, for future labour market policy with

\footnotetext{
37 It has to be noticed that this comparison of micro and macro estimates can provide no more than a hint on possible crowding out or substitution effects. Furthermore, the discussion about individual effects of training in East Germany has not jet settled (e.g. see Lechner 1999, Kraus, Puhani, and Steiner 1997). Puhani (1999) finds for Poland some hints on substitution effect of publicly funded training programs, but the results differ for different specification and data used.
} 
regard to PEPs it will be important to check for heterogenity of the effects with respect to individual characteristics of the participants as well as the PEP itself. For this tasks the availability of better data would be helpful.

${ }^{38}$ A prerequisite for a PEP is that it produces an output that is useful for the public, such as local infrastructure or social services. Apart from better employment chances participation in a PEP could rise the achievable wages for a participant. 


\section{Appendix A: Data}

Table 13: Number of Individuals when Selection Rules Were Applied, Unbalanced Panel

\begin{tabular}{|c|c|c|}
\hline & $\begin{array}{l}\text { Observations without } \\
\text { any PEP participation }\end{array}$ & $\begin{array}{l}\text { Observations with } \\
\text { PEP participation }\end{array}$ \\
\hline Raw data & 28,490 & 2,873 \\
\hline \multicolumn{3}{|l|}{ Age restriction } \\
\hline No or inconsistent age information & -425 & -30 \\
\hline No observation with age below 55 & $-6,074$ & -436 \\
\hline Younger than 22 in 1993 & $-3,513$ & -66 \\
\hline Remaining sample (in $\%$ of raw data) & $18,478(65 \%)$ & $2,341(81 \%)$ \\
\hline \multicolumn{3}{|l|}{ PEP information } \\
\hline Older than 52 when starting PEP & -0 & -92 \\
\hline $\begin{array}{l}\text { Observations with unknown start and end date of } \\
\text { PEPa) or with inconsistent PEP information }\end{array}$ & -0 & -451 \\
\hline Starting PEP before March 1991a) & -0 & -266 \\
\hline Remaining sample (in $\%$ of raw data) & $18,478(65 \%)$ & $1,532(53 \%)$ \\
\hline \multicolumn{3}{|l|}{$\begin{array}{l}\text { Insufficient number of observations or no useful information } \\
\text { contained }\end{array}$} \\
\hline Students ${ }^{\mathrm{b})}$ & -425 & -11 \\
\hline $\begin{array}{l}\text { Answered questionnaire only in Mar. } 92 \text { or only in } \\
\text { Sep. 97a) }\end{array}$ & $-3,545$ & -327 \\
\hline $\begin{array}{l}\text { Answered questionnaire only in Sep. 94, only in Sep. } \\
94 \text { and } 95 \text {, or only in Sep. 95b) }\end{array}$ & $-1,551$ & -25 \\
\hline Inconsistent regional information & -11 & -3 \\
\hline Remaining sample (in $\%$ of raw data) & $12,946(45 \%)$ & $1,166(41 \%)$ \\
\hline $\begin{array}{l}\text { Observations with missings in variables used for the estimation } \\
\text { of the propensity score }\end{array}$ & -381 & -43 \\
\hline Sample for estimating the propensity score (in $\%$ of raw data) & $12,565(44 \%)$ & $1,123(39 \%)$ \\
\hline
\end{tabular}

Notes: a) These observations do not provide any useable information in the context of this paper.

b) There is not a sufficient number of PEP participants in these groups.

Figure 4 presents an overview on the distribution of start respectively end dates of PEPs in our sample (see as well Table 4 and Figure 1 in Section 4.2). The sample used here and in the following descriptive statistics is the sample used for the estimation of the partial propensity score (12,565 NoPEP observations; 1,123 PEP observations), that is all selection rules were applied. See Table 13 for details. The number of observations used for the computations depends on the observability of the information in the sample. 


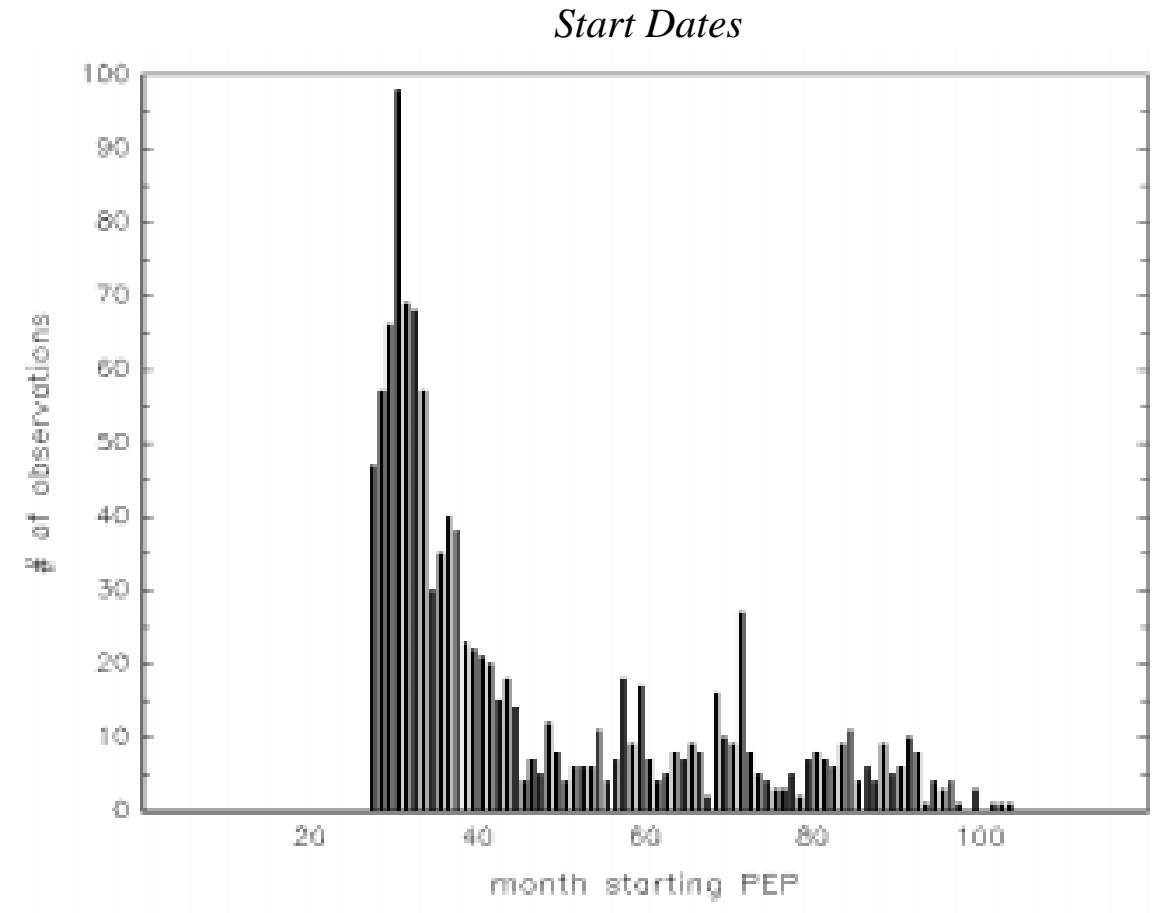

End Dates

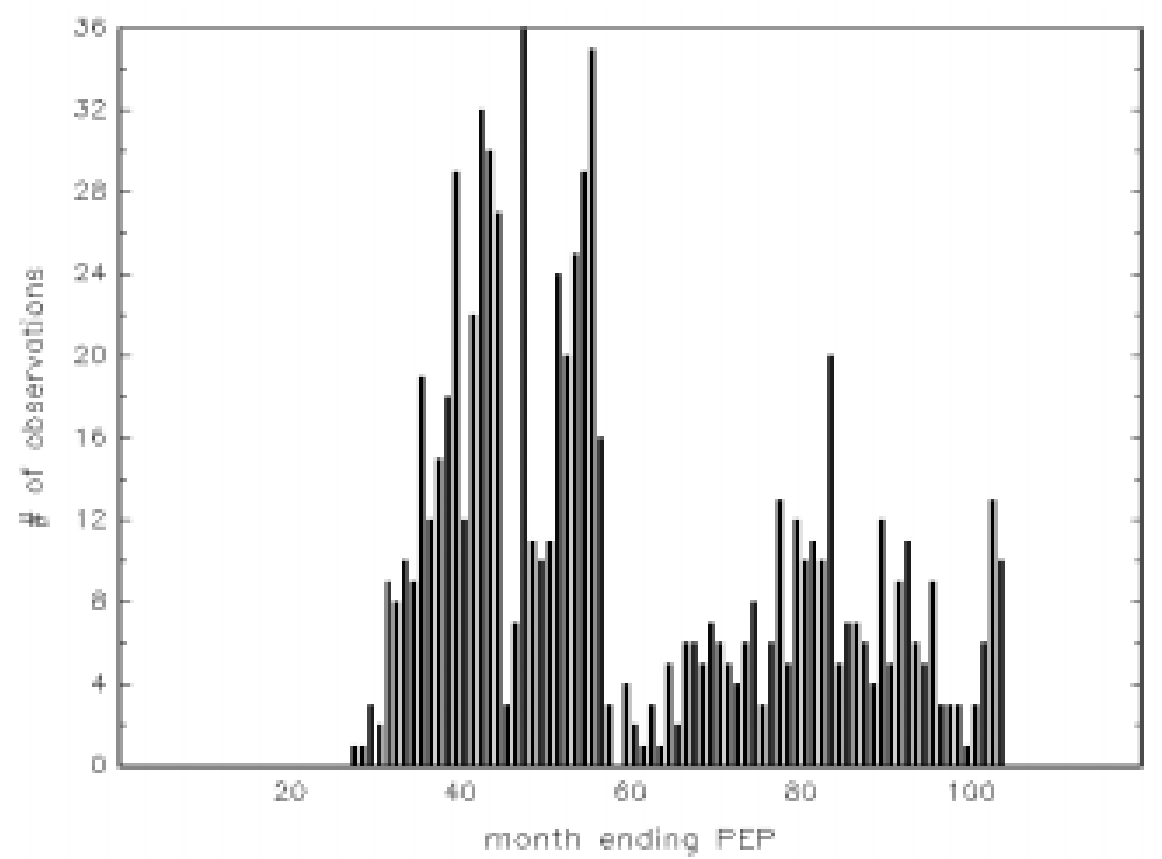

Note: $\quad \mathrm{X}$-axis: Time, measured in months ; Y-axis: number of observations. Time is presented in 'months since January 1989'; for example: March '92: 39; September '92: 45; September '93: 57; September '94: 69; September '95: 81; September '96: 93; September '97: 105. Start dates - and therefore end dates as well - earlier than 27 have been deleted (see Section 4.2). Number of valid observations for start dates: 1123; number of valid observations for end dates: 778 .

Table 14 provides information on the definition of variables used, Table 15 presents some comparable descriptive statistics for PEP participants and non-participants in the sample. 


\begin{tabular}{|c|c|c|c|}
\hline Category & Variable & Definition & Time concept \\
\hline Age & Age & Age in 1993 & Constant \\
\hline Gender & Female & Women (dummy) & Constant \\
\hline \multirow[t]{4}{*}{ Schooling } & $\begin{array}{l}\text { University entrance } \\
\text { degree }\end{array}$ & Abitur, highest German schooling degree & Constant \\
\hline & Medium & Mittlere Reife,10th class & Constant \\
\hline & Low & Hauptschulabschluss, 9th class & Constant \\
\hline & No degree & No degree & Constant \\
\hline \multirow[t]{3}{*}{$\begin{array}{l}\text { Vocational } \\
\text { degree }\end{array}$} & Vocational degree & $\begin{array}{l}\text { Level of highest vocational degree } \\
\text { 1: Partly vocational training (Teilfacharbeiter) } \\
\text { 2: Vocational training (Facharbeiter) } \\
\text { 3: Advanced vocational training (Meister, Techniker) } \\
\text { 4: Technical school (Fachschule) } \\
\text { 5: University degree }\end{array}$ & Variable \\
\hline & Technical school & Technical school (Fachschule) & Constant \\
\hline & University degree & University degree & Constant \\
\hline \multirow{3}{*}{$\begin{array}{l}\text { Labour market } \\
\text { status }\end{array}$} & Employed & In regular or irregular employment (including PEPS) & Variable \\
\hline & Unemployed & Registered as unemployed & Variable \\
\hline & Out of labour force & Not employed and not registered as unemployed & Variable \\
\hline \multirow[t]{3}{*}{ Current employer } & Position in firm & $\begin{array}{l}\text { Current or last known position in firm } \\
\text { 1: In education (Lehrling) } \\
\text { 2: Blue color worker (Arbeiter) } \\
\text { 3: White color worker (Angestellter) } \\
\text { 4: In public services (Beamter) } \\
\text { 5: Self-employed (Selbständiger) }\end{array}$ & Variable \\
\hline & Size of firm & $\begin{array}{l}\text { Employees of current or last known firm } \\
\text { 1: } 1 \text { to } 19 \\
\text { 2: } 20 \text { to } 49 \\
\text { 3: } 50 \text { to } 99 \\
\text { 4: } 100 \text { to } 999 \\
\text { 5: } 1000 \text { or more }\end{array}$ & Variable \\
\hline & Industrial sector & $\begin{array}{l}\text { Industrial sector of current or last known employer; } \\
\text { dummies: agricultural, chemical, and public sector }\end{array}$ & Variable \\
\hline \multirow[t]{3}{*}{$\begin{array}{l}\text { Labour market } \\
\text { indicators }\end{array}$} & $\begin{array}{l}\text { Unemployment } \\
\text { rate in region }\end{array}$ & $\begin{array}{l}\text { Separated for eight regions, at month of interview, } \\
\text { unemployment defined as: officially unemployed or } \\
\text { participating in active labour market policy }\end{array}$ & Variable \\
\hline & $\begin{array}{l}\text { Unemployment } \\
\text { rate in region } \\
\text { (mean) }\end{array}$ & $\begin{array}{l}\text { Separated for eight regions, mean (1991 to 1997), } \\
\text { unemployment defined as: officially unemployed or } \\
\text { participating in active labour market policy }\end{array}$ & Constant \\
\hline & $\begin{array}{l}\text { PEP rate in region } \\
\text { (mean) }\end{array}$ & $\begin{array}{l}\text { Persons employed in PEP per regular employed, } \\
\text { separated for eight regions, mean (1991 to 1997) }\end{array}$ & Constant \\
\hline \multirow[t]{2}{*}{ Living in } & Region & $\begin{array}{l}\text { Living in one of eight regions in Sachsen-Anhalt } \\
\text { (dummies), separated according to the responsibility } \\
\text { of the labour offices (Arbeitsamtsbezirke) }\end{array}$ & Constant \\
\hline & City and area & $\begin{array}{l}\text { Living in one of } 24 \text { local divisions (dummies): } \\
3 \text { cities (larger cities, kreisfreie Städte) and } 21 \text { areas } \\
\text { (rural areas and smaller cities, Landkreise) }\end{array}$ & Constant \\
\hline $\begin{array}{l}\text { Observeability in } \\
\text { panel }\end{array}$ & $\begin{array}{l}\text { Answered only } \\
\text { in ... }\end{array}$ & $\begin{array}{l}\text { The date (in month and year) or all dates at which the } \\
\text { person answered a questionnaire }\end{array}$ & Constant \\
\hline
\end{tabular}


Table 15: Descriptive Statistics of Selected Variables for Persons With and Without PEP

\begin{tabular}{|c|c|c|}
\hline & \multicolumn{2}{|c|}{$\begin{array}{l}\text { Mean in subsample or } \\
\text { share in subsample in \% }\end{array}$} \\
\hline Age (1993) & 38.5 years & 38.8 years \\
\hline Gender. Female & 52 & 52 \\
\hline Schooling: Highest degree & & \\
\hline University entrance degree (Abitur) & 28 & 23 \\
\hline Medium (Klasse 10) & 54 & 54 \\
\hline Low (Klasse 9 or no degree) & 18 & 23 \\
\hline University degree & 18 & 15 \\
\hline Technical school (Fachschule) & 24 & 21 \\
\hline Current employer. Position in firm in (average value) & & \\
\hline March 1991 / Sep. 1992 & $2.8 / 2.7$ & $2.8 / 2.4$ \\
\hline Sep. 1994 / Sep. 1996 / Sep. 1997 & $2.8 / 2.8 / 2.9$ & $2.6 / 2.6 / 2.6$ \\
\hline Current employer. Size of firm in (average value) & & \\
\hline March 1991 / March 1992 / Sep. 1992 & n.a. / $2.8 /$ n.a. & n.a. / $2.8 /$ n.a. \\
\hline Sep. 1994 / Sep. 1996 / Sep. 1997 & $2.5 / 2.4 / 2.4$ & $2.5 / 2.2 / 2.1$ \\
\hline Current employer: Industrial sector: Agricultural & & \\
\hline $\begin{array}{l}\text { March } 1991 \text { / Sep. } 1992 \text { / Sep. } 1994 \text { / Sep. } 1996 \text { / Sep. } 1997 \\
\text { Current employer: Industrial sector: Chemical }\end{array}$ & $7 / 5 / 4 / 3 / 3$ & $21 / 10 / 8 / 3 / 5$ \\
\hline $\begin{array}{l}\text { March } 1991 \text { / Sep. } 1992 \text { / Sep. } 1994 \text { / Sep. } 1996 \text { / Sep. } 1997 \\
\text { Current employer: Industrial sector: Public }\end{array}$ & $7 / 5 / 4 / 4 / 4$ & $17 / 13 / 9 / 8 / 3$ \\
\hline March 1991 / Sep. 1992 / Sep. 1994 / Sep. 1996 / Sep. 1997 & $9 / 9 / 12 / 13 / 14$ & $2 / 19 / 13 / 21 / 14$ \\
\hline Observability in panel: Answered questionnaire only in & & \\
\hline Mar. ' 92 , Sep. '92 & 39 & 30 \\
\hline Sep. '93 & 19 & 13 \\
\hline Sep. '93, Sep. '94 & 11 & 7 \\
\hline Sep.' 93, Sep. '94, Sep. '95 & 3 & 3 \\
\hline Sep.' 93, Sep. '94, Sep. '95, Sep. '96 & 2 & 3 \\
\hline Sep.' 93, Sep. '94, Sep. '95, Sep. '96, Sep. '97 & 6 & 10 \\
\hline Sep. '95, Sep. '96 & 1 & 2 \\
\hline Sep. '95, Sep. '96, Sep. '97 & 2 & 4 \\
\hline Sep.' 96 & 7 & 13 \\
\hline Sep. '96, Sep. '97 & 7 & 12 \\
\hline
\end{tabular}

To be continued. 


\begin{tabular}{|c|c|c|}
\hline \multirow[b]{2}{*}{ Employment: Registered as unemployed in } & \multicolumn{2}{|c|}{$\begin{array}{l}\text { No PEP PEP } \\
\text { Mean in subsample or } \\
\text { share in subsample in } \%\end{array}$} \\
\hline & & \\
\hline March 1991 / Sep. 1992 / Sep. 1993 & $6 / 10 / 16$ & $16 / 15 / 47$ \\
\hline Sep. 1994 / Sep. 1996 / Sep. 1997 & $9 / 10 / 11$ & $25 / 30 / 42$ \\
\hline \multicolumn{3}{|l|}{ Employment: Employed in } \\
\hline March 1991 / Sep. 1992 / Sep. 1993 & 89 / 81 / 81 & $79 / 78 / 51$ \\
\hline Sep. 1994 / Sep 1996 / Sep 1997 & $85 / 84 / 83$ & $68 / 61 / 47$ \\
\hline Unemployment rate in region (mean over time 91-97) & 21 & 22 \\
\hline PEP rate in region (mean over time 91-97) & 4 & 4 \\
\hline \multicolumn{3}{|l|}{ Living in } \\
\hline Region of Dessau & 10 & 10 \\
\hline Region of Halberstadt & 10 & 11 \\
\hline Region of Halle & 19 & 13 \\
\hline Region of Magdeburg & 24 & 25 \\
\hline Region of Merseburg & 13 & 12 \\
\hline Region of Sangerhausen & 9 & 12 \\
\hline Region of Stendal & 10 & 10 \\
\hline Region of Wittenberg & 6 & 7 \\
\hline City of Dessau & 4 & 2 \\
\hline City of Halle & 12 & 5 \\
\hline City of Magdeburg & 11 & 8 \\
\hline Area of Altmarkkreis Salzwedel & 4 & 4 \\
\hline Area of Aschersleben-Straßfurt & 4 & 6 \\
\hline Area of Anhalt-Zerbst & 3 & 3 \\
\hline Area of Bernburg & 2 & 3 \\
\hline Area of Bitterfeld & 4 & 7 \\
\hline Area of Bördekreis & 3 & 3 \\
\hline Area of Burgenlandkreis & 5 & 5 \\
\hline Area of Jerichower Land & 3 & 2 \\
\hline Area of Halberstadt & 3 & 2 \\
\hline Area of Köthen & 2 & 3 \\
\hline Area of Mansfelder Land & 4 & 5 \\
\hline Area of Merseburg-Querfurt & 5 & 5 \\
\hline Area of Ohre-Kreis & 3 & 4 \\
\hline Area of Quedlinburg & 3 & 6 \\
\hline Area of Saalekreis & 2 & 2 \\
\hline Area of Sangerhausen & 3 & 3 \\
\hline Area of Schönbeck & 3 & 3 \\
\hline Area of Stendal & 6 & 6 \\
\hline Area of Weißenfels & 3 & 2 \\
\hline Area of Wernigerode & 4 & 3 \\
\hline Area of Wittenberg & 6 & 7 \\
\hline Max. number of observations & 12,565 & 1,123 \\
\hline
\end{tabular}

Note: Some statistics generated with less observations because of missing information. 


\section{Appendix B: Econometrics}

\section{B.1 Matching Protocol}

This section gives the details of the matching protocol used for the evaluations. Here $V$ contains the time-constant variables used in the estimation of the propensity score, $M$ the time varying variables to be included in the matching separately.

Step 1: Split observations in two exclusive pools according to whether they participated in a PEP (P-pool) or not (C-pool).

Step 2: $\quad$ Draw randomly an observation in P-pool (denoted by $i$ ) and remove from P-pool.

Step 3: Take the observations in C-pool and compute the time varying variables $M$ in relation to the start date of observation $i$.

Step 4: Denote these and perhaps other variables already included in $V$ as $\tilde{m}_{j}$ and $\tilde{m}_{i}$, respectively. Define a distance between each comparison $j$ and $i$ as $d(j, i)=$ $\left(v_{j} \hat{\beta}, \tilde{m}_{j}\right)^{\prime}-\left(v_{i} \hat{\beta}, \tilde{m}_{i}\right)^{\prime}$, where $v \hat{\beta}$ denotes the estimated partial propensity score. Choose comparison $j$ such that it has the smallest Mahalanobis distance $a(j, i)=d(j, i)^{\prime} W d(j, i) . W$ denotes the inverse of the estimated variance of $(v \hat{\beta}, \tilde{m})^{\prime}$ in the C-pool (computed for a given start date).

Step 5: $\quad$ Remove $j$ from C-pool.

Step 6: If there are any observations in the P-pool left, start again with step 2.

This matching algorithm is close to the one called partial propensity score suggested by Lechner (1999). See this paper for more details and a comparison to other ways of handling time varying variables within a matching framework when the programmes have individually different start dates. When matching is done for the bias correction samples ( $\tau$-samples, $\tau=-1$ ), step 3 has to be changed as follows:

Step 3- $\tau$ : For all treated observations compute an artificial start date as month of the last 
interview before PEP minus the duration of PEP. Then, take the comparisons and compute the time varying variables $m$ in relation to the artificial start date of observation $i$.

\section{B.2 Variance of $\hat{\theta}_{t-\tau, N}^{B S}$ for Unbalanced Panels}

In this appendix, $\hat{\theta}_{t-\tau, N}^{B S A}$ is generalized to the case of random attrition. In that case there are not only different comparisons in periods $t$ and $\tau$, but also different treated observations. Denote the number of treated observations observed in period $t(\tau)$ by $N_{t}^{p} \leq N^{p} \quad\left(N_{\tau}^{p} \leq N^{p}\right)$. Furthermore, denote the set of observations observed in period $t(\tau)$ by $D_{t}\left(D_{\tau}\right)$.

$\hat{\theta}_{t-\tau, N}^{B S A}=\frac{1}{N_{t}^{p}} \sum_{i=1}^{N^{p}} \underline{1}\left(i \in D_{t}\right)\left(y_{i, t}^{p}-y_{j(i), t}^{n}\right)-\frac{1}{N_{\tau}^{p}} \sum_{i=1}^{N^{p}} \underline{1}\left(i \in D_{\tau}\right)\left(y_{i, \tau}^{p}-y_{j(i), \tau}^{n}\right) ; \quad N^{p}<j, j^{\prime} \leq N$.

$1(\cdot)$ denotes an indicator function that is one if its argument is true and zero otherwise. Of course, in practise no comparison observation is matched to a treated observation that is not observed in the particular sample. To obtain the variance we may rewrite Equation (B.1) as follows:

$\hat{\theta}_{t-\tau, N}^{B S A}=\sum_{i=1}^{N^{p}}\left\{\left[\underline{1}\left(i \in D_{t}\right) \frac{y_{i, t}^{p}}{N_{t}^{p}}-\underline{1}\left(i \in D_{\tau}\right) \frac{y_{i, \tau}^{p}}{N_{\tau}^{p}}\right]-\left[\underline{1}\left(i \in D_{t}\right) \frac{y_{j(i), t}^{n}}{N_{t}^{p}}-\underline{1}\left(i \in D_{\tau}\right) \frac{y_{j(i), \tau}^{n}}{N_{\tau}^{p}}\right]\right\}$.

Since the comparison and the treated observations are independent, we can estimate the variance of the two expressions in the square brackets separately.

$\operatorname{Var}\left(\hat{\theta}_{t-\tau, N}^{B S A}\right)=\operatorname{Var}\left(P_{t-\tau}\right)+\operatorname{Var}\left(C_{t-\tau}\right) ; \quad\left(\hat{\theta}_{t-\tau, N}^{B S A}=P_{t-\tau}-C_{t-\tau}\right)$ 


$$
\begin{aligned}
\operatorname{Var}\left(p_{t-\tau}\right) & =N^{p} \operatorname{Var}\left[\underline{1}\left(i \in D_{t} \wedge i \in D_{\tau}\right)\left(\frac{y_{i, t}}{N_{t}^{p}}-\frac{y_{i, \tau}}{N_{\tau}^{p}}\right)\right]+ \\
& +\frac{N^{p}}{N_{t}^{p}} \operatorname{Var}\left[\underline{1}\left(i \in D_{t} \wedge i \notin D_{\tau}\right)\left(y_{i, t}\right)\right]+\frac{N^{p}}{N_{\tau}^{p}} \operatorname{Var}\left[\underline{1}\left(i \notin D_{t} \wedge i \in D_{\tau}\right)\left(y_{i, \tau}\right)\right] .
\end{aligned}
$$

The three variances needed to compute $\operatorname{Var}\left(P_{t-\tau}\right)$ can be estimated by the empirical variances in the respective three subsamples defined by the observability of the treated. The estimation of $\operatorname{Var}\left(C_{t-\tau}\right)$ follows exactly the same rule.

\section{Appendix C: Match Quality}

A basic requirement for a successful implementation of a matching algorithm is a sufficiently large overlap between the distributions of the conditioning variables in both sub-samples. Figure 5 shows that this is the case for the balancing score. The fact that matching is successful for key time variant variables as seen in Section 6 indicates that this is also the case for those variables.

Table 16 shows the difference of the treated and comparison observations for the variables appearing in the propensity score. The final two rows of Table 16 contain two summary statistics of the match for the variables mentioned in the table and some further variables. MSB denotes the median of the absolute biases of the means (i.e. the differences in means) normalised by the average standard deviation (e.g. Rosenbaum and Rubin, 1985). JW denotes a quadratic distance measure for the mean biases weighted by the inverses of their covariance matrix (see note on Table 16 for details). The table shows that the respective matched comparison samples and PEP participants do not differ significantly with respect to the variables included in the propensity score (here for the case of using time varying variables of the last interview before a PEP only). However, it could also be seen that the means of the evaluation sample and the bias correction sample differ in particular with respect to gender. 
This is as expected because for the latter more of the individual labour market 'history' is needed than for the former, thus the PEPs tend to take place later in the bias correction sample than in the evaluation sample. Since the policy of the labour office changed over time, this results in an increase of women in PEPs as is reflected in the numbers of Table 16. This does not necessarily imply that the analysis given in the main body of the text is flawed, because all what is needed is a time-constant bias. However, this assumption appears to be more reasonable if the distribution of characteristics is also constant over time. The gender-specific results, presented in Table 12 in the main body of the paper, indicate that this unequal distribution of gender in the two samples does not have a significant impact on the results.

Figure 5: Support of the Propensity Score for Participants and Non-Participants

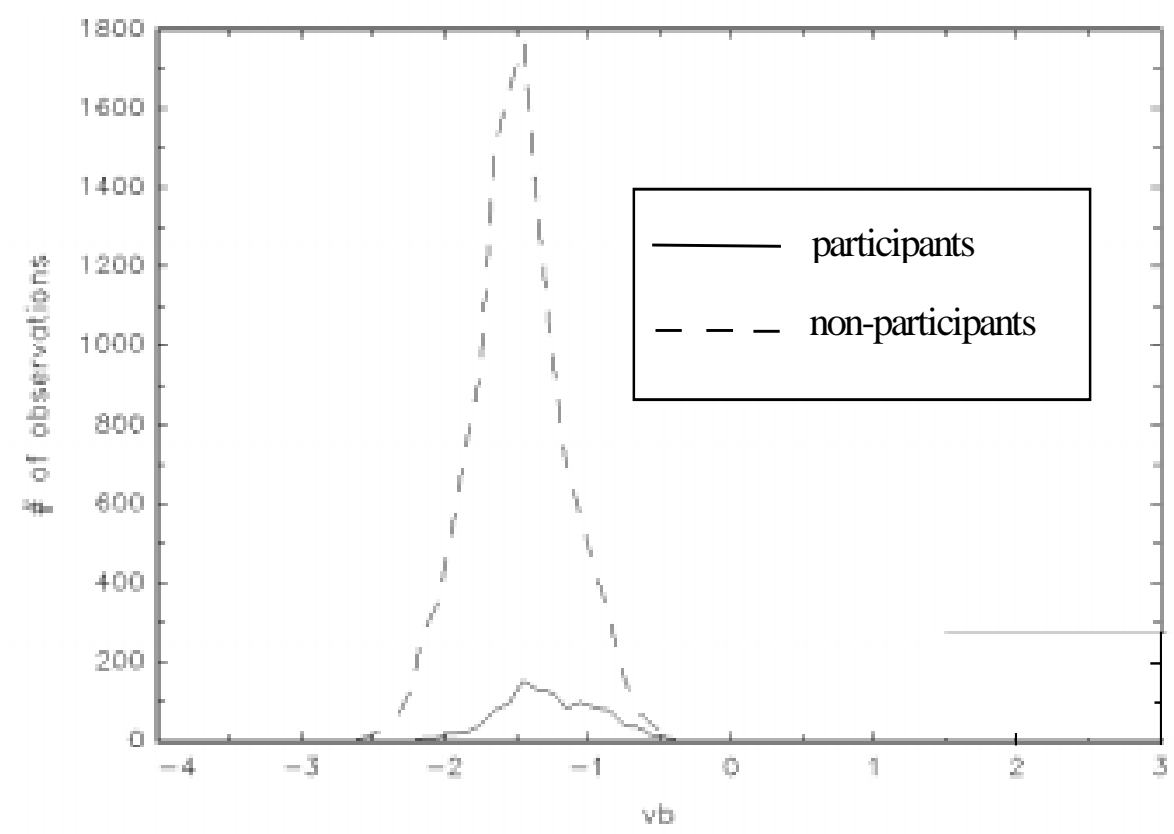

Note: Number of observations: 13,688 observations (1,123 participants; 12,565 non-participants). 
Table 16: Descriptive Statistics of Selected Variables of PEP and Matched Comparison Samples

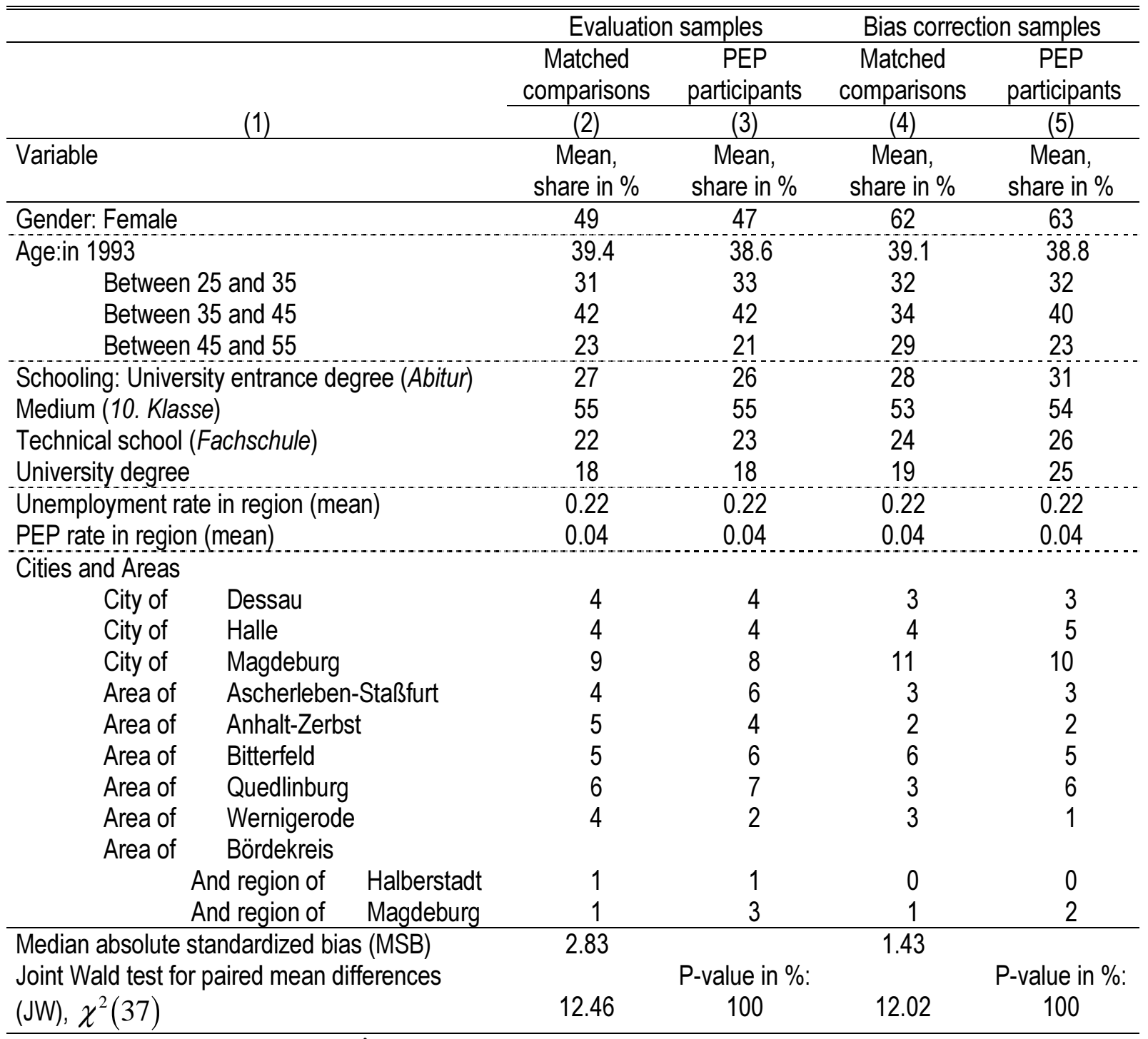

Note: (2) and (4) matched on $v \hat{\beta}$ selected v-variables and $\mathrm{m}$ (yearly)-variables (partial). v-variables used for the additional conditioning are dummy variables indicating whether the individual has a valid interview in the respective year. m-variables are unemployment, employment, highest vocational degree, (last) position in firm, size of (last) firm, unemployment rate in the region measured for the last interview before PEP for evaluation samples and bias correction samples $(\tau=-1) ; \operatorname{MSB}=\underset{k}{\operatorname{median}}\left(b^{k}\left[\sqrt{\left(s^{2}\left(x_{i}^{k}\right)+s^{2}\left(x_{(i)}^{k}\right)\right) / 2}\right]^{-1}\right)$;

$J W=N^{t} b\left[s^{2}\left(x_{i}^{k}-x_{(i)}^{k}\right)\right]^{-1} b ; b^{k}=\left[N^{t}\right]^{-1} \sum_{i=1}^{N^{t}}\left(x_{i}^{k}-x_{(i)}^{k}\right) x_{(i)}$ denotes the value of the comparison observation matched to the treated observation i. $\mathrm{s}^{2}(\mathrm{a})$ denotes the empirical variance of a. $b=\left(b^{1}, \ldots, b^{k}, \ldots, b^{K}\right)$ '. Asymptotically, $\chi^{2}(K)$ should be a good approximation for the distribution of JW when there are no systematic differences of the $K$ attributes given in the table for the matched pairs.

More information can be found in Lechner (1999). 


\section{Appendix D: Evaluation Results for Different Specifications}

To reduce the bias of CIA further, the results presented in the following Tables 17 and 18 are based on a specification of $X$ that includes the same variables as the version of $X$ used for the results presented in Tables 10 and 11, but adding the values for another interview prior to a PEP for the time varying variables. The match quality with respect to unemployment is again good. The results for the bias correction sample indicate again a positive bias for the CIA results, although further reduced. However, probably due to the reduced sample size $\hat{\theta}_{t, N}^{\mathrm{CIA}}$ is not significantly different from zero. Therefore, it is not surprising that $\hat{\theta}_{t-\tau, N}^{\text {BSA }}$ is not significantly different from zero as well.

Table 17: $\hat{\theta}_{N}^{\mathrm{CIA}}$ Computed with Time-Varying Matching Variables Two Periods Prior to PEP

\begin{tabular}{|c|c|c|c|c|c|c|c|c|c|c|}
\hline \multirow[b]{2}{*}{ Period } & \multicolumn{3}{|c|}{ Evaluation sample } & \multicolumn{3}{|c|}{ Bias correction sample } & \multirow[b]{2}{*}{ Period } & \multicolumn{3}{|c|}{ Evaluation sample } \\
\hline & $\hat{\theta}_{t, N}^{\mathrm{CIA}}$ & P-value & Obs. & $\hat{\theta}_{\tau, N}^{\mathrm{CIA}}$ & P-value & Obs. & & $\hat{\theta}_{t, N}^{\mathrm{CIA}}$ & P-value & Obs. \\
\hline-1 & 0 & 1.00 & 70 & 23 & .015 & 47 & 1 & 4 & .60 & 70 \\
\hline-2 & -1 & .86 & 71 & 4 & .67 & 47 & 2 & 15 & .24 & 27 \\
\hline-3 & 11 & .37 & 28 & 0 & 1.00 & 47 & 3 & 10 & .67 & 10 \\
\hline Note: & $\begin{array}{l}X \text { used fo } \\
\text { employm } \\
\text { public), } \\
\text { interviews }\end{array}$ & & & & & & & rticular & & \\
\hline
\end{tabular}

Table 18: $\hat{\theta}_{t-\tau, N}^{\mathrm{BSA}}$ Computed with Time-Varying Matching Variables Two Periods Prior to PEP

\begin{tabular}{ccccccc}
\hline \hline \multirow{2}{*}{ Period } & $\hat{E}\left(Y_{t}^{p} \mid S=1\right)$ & $\hat{E}\left(Y_{t}^{n} \mid S=1\right)$ & $\hat{\theta}_{t-\tau, N}^{\text {BSA }}$ & P-value & Obs. t & Obs. $\tau$ \\
\hline 1 & 39 & 58 & -20 & .092 & 70 & 47 \\
2 & 37 & 46 & -9 & .59 & 27 & 47 \\
3 & 50 & 63 & -13 & .60 & 10 & 47 \\
\hline Note: & See note on Table 17. & & & &
\end{tabular}

The following Tables 19 and 20 contain again results similar to Tables 10 and 11 in the main body of the text. However, the variables related to the (last) employer and to vocational degrees as well as the regional unemployment rate are not used in the matching. 
Table 19: $\hat{\theta}_{N}^{\mathrm{CIA}}$ Computed with a Reduced Set of Time-Varying Matching Variables

\begin{tabular}{|c|c|c|c|c|c|c|c|c|c|c|}
\hline \multirow[b]{2}{*}{ Period } & \multicolumn{3}{|c|}{ Evaluation sample } & \multicolumn{3}{|c|}{ Bias correction sample } & \multirow[b]{2}{*}{ Period } & \multicolumn{3}{|c|}{ Evaluation sample } \\
\hline & $\hat{\theta}_{t, N}^{\mathrm{CIA}}$ & P-value & Obs. & $\hat{\theta}_{\tau, N}^{\mathrm{CIA}}$ & P-value & Obs. & & $\hat{\theta}_{t, N}^{\mathrm{CIA}}$ & $\mathrm{P}$-value & Obs. \\
\hline-1 & 0 & .92 & 231 & 35 & .000 & 144 & 1 & 14 & .001 & 231 \\
\hline-2 & 8 & .36 & 67 & 1 & .89 & 143 & 2 & 8 & .20 & 88 \\
\hline-3 & 14 & .22 & 29 & 8 & .37 & 52 & 3 & 7 & .54 & 27 \\
\hline
\end{tabular}

Table 20: $\hat{\theta}_{t-\tau, N}^{\mathrm{BSA}}$ Computed with a Reduced Set of Time-Varying Matching Variables

\begin{tabular}{cccccrc}
\hline \hline \multirow{2}{*}{ Period } & $\hat{E}\left(Y_{t}^{p} \mid S=1\right)$ & $\hat{E}\left(Y_{t}^{n} \mid S=1\right)$ & $\hat{\theta}_{t-\tau, N}^{\mathrm{BSA}}$ & P-value & Obs. t & \multirow{2}{*}{ Obs. $\tau$} \\
\hline 1 & 35 & 56 & -21 & .001 & 231 & 144 \\
2 & 25 & 52 & -27 & .001 & 88 & 144 \\
3 & 29 & 57 & -27 & .040 & 27 & 144 \\
\hline Note: & See note on Table 19. & & & & &
\end{tabular}

Other specifications were used as well, e.g. the combination of the above specifications, splitting for gender, and/or using employment and out of labour force as variables of interest. The results did not differ substantially from the results presented in the paper. 


\section{References}

Angrist, J.D., G.W. Imbens, and D.B. Rubin, 1996, Identification of Causal Effects Using Instrumental Variables, Journal of the American Statistical Association 91, 444-472, incl. discussion by J.J. Heckman, R.A. Moffitt, J.M. Robins, S. Greenland, and R.P. Rosenbaum.

Bera, A., Jarque, C. and Lee, C.F. (1984): "Testing the Normality Assumption in Limited Dependent Variable Models", International Economic Review, 25, 563-578.

Brinkmann, C. and C. Wolfinger, 1994, Aktive Arbeitsmarktpolitik mit einem neuen Instrument: Pauschalierte Lohnkostenzuschüsse zur Arbeitsförderung ( $\$ 249 \mathrm{~h}$ AFG), IAB werkstattberichte 9/1994, Institut für Arbeitsmarkt- und Berufsforschung der Bundesanstalt für Arbeit.

Cockx, B. and G. Ridder, 1996, Social Employment of Welfare Recipients in Belgium: An Evaluation, mimeo, Université Catholique de Louvain.

Davidson, R. and J.G. MacKinnon, 1984, Consistent Specification Tests for Logit and Probit Regressions, Journal of Econometrics, 25, 241-262.

Eichler, M. and M. Lechner, 1998, An Evaluation of Public Employment Programmes in the East German State of Sachsen-Anhalt, Beiträge zur angewandten Wirtschaftsforschung \# 560-98, University of Mannheim.

Emmerich, K., 1993, Mega-ABM: Bestandsaufnahme und Perspektiven, IAB werkstattberichte 9/1993, Institut für Arbeitsmarkt- und Berufsforschung der Bundesanstalt für Arbeit.

Heckman, J.J. and V.J. Hotz, 1989, Choosing Among Alternative Nonexperimental Methods for Estimating the Impact of Social Programs: The Case of Manpower Training, Journal ot the American Statistical Association $84,862-874$.

Heckman, J.J., H. Ichimura, and P. Todd, 1997, Matching as an Econometric Evaluation Estimator: Evidence from Evaluating a Job Training Programme, Review of Economic Studies 64, 605-654.

Heckman, J.J., R.J LaLonde, and J.A. Smith, 1999, The Economics and Econometrics of Active Labor Market Programs, forthcoming in: O. Ashenfelter and D. Card, eds., Handbook of Labor Economics, Vol. III.

Heckman, J.J., L. Lochner, J.A. Smith, and C. Taber, 1998, The Effects of Goverment Tax, Education and Training Policy on Human Capital Investment and Wage Inequality, in: H. Koenig, ed., Proceedings of the Third Symposium of the German-American Academic Council Foundation 1998, 305-339.

Heckman, J.J. and J.A. Smith, 1999, The Pre-Programme Earnings Dip and the Determinants of Participation in a Social Programme. Implications for Simple Programme Evaluation Strategies, The Economic Journal 109, 313-348.

Holland, P.W., 1986, Statistics and Causal Inference, Journal of the American Statistical Association 81, $945-$ 970, incl. discussion.

Hübler, O., 1997, Evaluation beschäftigungspolitischer Maßnahmen in Ostdeutschland, Jahrbücher für Nationalökonomie und Statistik 216/1, 21-44.

Kraus, F., P.A. Puhani, and V. Steiner, 1997, Employment Effects of Publically Financed Training Programs the East German Experience, Discussion Paper \# 97-33, Zentrum für Europäische Wirtschaftsforschung.

Kraus, F., P.A. Puhani, and V. Steiner, 1998, Do Public Work Programs Work? Some Unpleasant Results from the East German Experience, Discussion Paper \# 98-07, Zentrum für Europäische Wirtschaftsforschung.

LaLonde, R.J., 1995, The Promise of Public Sector-Sponsered Training Programes, Jounal of Economic Perspectives 9, 149-168.

Lechner, M., 1999, Earnings and Employment Effects of Continuous Off-the-Job Training in East Germany after Unification, Journal of Business \& Economic Statistics 17.

Meyer, B.M., 1995, Natural and Quasi-Experiments in Economics, Journal of Business \& Economic Statistics 13, 151-161.

Orme, C., 1990, The Small Sample Performance of the Information Matrix Test for Binary Data Models, Journal of Econometrics 4, 529-559.

Puhani, P.A., 1999, Evaluating Active Labour Market Policies, Empirical Evidence for Poland During Transition, ZEW Economic Studies, 5, Heidelberg: Physica/Springer-Verlag.

Rosenbaum, P.R. and D.B. Rubin, 1983, The Central Role of the Propensity Score in Observational Studies for Causal Effects, Biometrica 70, 41-50. 
Rosenbaum, P.R. and D.B. Rubin, 1985, Constructing a Control Group Using Multivariate Matched Sampling Methods That Incorporate the Propensity Score, The American Statistician 39, 33-38.

Roy, A.D., 1951, Some Thoughts on the Distribution of Earnings, Oxford Economic Papers 3, 135-146.

Rubin, D.B., 1974, Estimating Causal Effects of Treatments in Randomized and Nonrandomized Studies, Journal of Educational Psychology 66, 688-701.

Rubin, D.B., 1977, Assignment to Treatment Group on the Basis of a Covariate, Journal of Educational Statistics 2, 1-26.

Sobel, M.E., 1994, Causal Inference in the Social and Behavioral Sciences, in: G. Arminger, C.C. Clogg, and M.E. Sobel, eds., Handbook of Statistical Modeling for the Social and Behavioral Sciences, (Plenum Press, New York), 1-38.

Spitznagel, E., 1993, Zur Brückenfunktion der Allgemeinen Maßnahmen zur Arbeitsbeschaffung (ABM), IAB werkstattbericht 21/1993, Institut für Arbeitsmarkt- und Berufsforschung der Bundesanstalt für Arbeit.

Steiner, V. and F. Kraus, 1995, Haben Teilnehmer an Arbeitsbeschaffungsmaßnahmen in Ostdeutschland bessere Wiederbeschäftigungschancen als Arbeitslose?, in: V. Steiner and L. Bellmann, eds., Mikroökonometrie des Arbeitsmarktes, Beiträge aus der Arbeitsmarkt- und Berufsforschung 192, 387-423.

Steiner, V., E. Wolf, J. Egeln, M. Almus, H. Schrumpf, and P. Feldotto, 1998, Strukturanalyse der Arbeitsmarktentwicklung in den neuen Bundesländern, ZEW Wirtschaftsanalysen, 30, Baden-Baden: Nomos.

White, H., 1982, Maximum Likelihood Estimation of Misspecified Models, Econometrica 50, 1-25.

Wiener, B., 1995, Wegweiser zu den Arbeitsmarktdaten Sachsen-Anhalt, Forschungsbeiträge zum Arbeitsmarkt in Sachsen-Anhalt 8, Ministerium für Arbeit, Soziales und Gesundheit des Landes Sachsen-Anhalt.

Wolfinger, C., 1994, Neue Bundesländer: Lohnkostenzuschüsse nach §249h AFG - Eine Zwischenbilanz Teil II: Teilnehmerstrukturen, IAB Kurzberichte 11/1994, Institut für Arbeitsmarkt- und Berufsforschung der Bundesanstalt für Arbeit.

Wolfinger, C., 1995, Neue Bundesländer: Lohnkostenzuschüsse nach §249h AFG: Die investive Komponente steht im Vordergrund, IAB Kurzberichte 2/1995, Institut für Arbeitsmarkt- und Berufsforschung der Bundesanstalt für Arbeit.

Zentrum für Sozialforschung, 1998, Informations-Bulletin zu den Arbeitsmarktdaten Sachsen-Anhalt 2/1998, Zentrum für Sozialforschung Halle e.V. 